\title{
Diversity at the Mla Powdery Mildew Resistance Locus from Cultivated Barley Reveals Sites of Positive Selection
}

\author{
Sabine Seeholzer, ${ }^{1}$ Takashi Tsuchimatsu, ${ }^{1,2}$ Tina Jordan, ${ }^{1}$ Stéphane Bieri, ${ }^{1}$ Simone Pajonk, ${ }^{3}$ \\ Wenxiang Yang, ${ }^{4}$ Ahmed Jahoor, ${ }^{5}$ Kentaro K. Shimizu, ${ }^{1}$ Beat Keller, ${ }^{1}$ and Paul Schulze-Lefert ${ }^{3}$ \\ ${ }^{1}$ Plant Biology, University of Zürich, Zürich, Switzerland; ${ }^{2}$ Department of General Systems Studies, University of Tokyo, \\ Tokyo, Japan; ${ }^{3}$ Department of Plant-Microbe Interactions, Max-Planck-Institut für Züchtungsforschung, Köln, Germany; \\ ${ }^{4}$ Department of Plant Pathology, Agricultural University of Hebei; Biocontrol Centre of Plant Pathogens and Pests, \\ Hebei Province, China; ${ }^{5}$ Department of Agricultural Sciences, Copenhagen University, Frederiksberg, Denmark
}

Submitted 28 October 2009. Accepted 9 December 2009.

The Mla locus in barley (Hordeum vulgare) conditions isolate-specific immunity to the powdery mildew fungus (Blumeria graminis f. sp. hordei) and encodes intracellular coiled-coil (CC) domain, nucleotide-binding (NB) site, and leucine-rich repeat (LRR)-containing receptor proteins. Over the last decades, genetic studies in breeding material have identified a large number of functional resistance genes at the Mla locus. To study the structural and functional diversity of this locus at the molecular level, we isolated 23 candidate MLA cDNAs from barley accessions that were previously shown by genetic studies to harbor different Mla resistance specificities. Resistance activity was detected for 13 candidate MLA cDNAs in a transient gene-expression assay. Sequence alignment of the deduced MLA proteins improved secondary structure predictions, revealing four additional, previously overlooked LRR. Analysis of nucleotide diversity of the candidate and validated MLA cDNAs revealed 34 sites of positive selection. Recombination or gene conversion events were frequent in the first half of the gene but positive selection was also found when this region was excluded. The positively selected sites are all, except two, located in the LRR domain and cluster in predicted solvent-exposed residues of the repeats 7 to 15 and adjacent turns on the concave side of the predicted solenoid protein structure. This domainrestricted pattern of positively selected sites, together with the length conservation of individual LRR, suggests direct binding of effectors to MLA receptors.

The innate immune system of plants engages two classes of immune receptors to detect the presence of non-self molecular structures outside and inside of plant cells. One class comprises membrane-resident pattern recognition receptors that

Current address of S. Seeholzer: Baxter AG, Volketswil, Switzerland.

Current address of S. Bieri: BASF Plant Science GmbH, Limburgerhof, Germany.

Current address of S. Pajonk: Heidelberg Institute of Plant Sciences, Bioquant BQ23, University of Heidelberg, Heidelberg, Germany.

Corresponding authors: Beat Keller; Telephone: +41 44 634-8230; Fax: +41 44 634-8204; E-mail: bkeller@botinst.uzh.ch and Paul SchulzeLefert; Telephone: +49 2215062 350; Fax: +49-2215062-353; E-mail: schlef@mpiz-koeln.mpg.de

* The $\boldsymbol{e}$-Xtra logo stands for "electronic extra" and indicates that four supplementary tables and two supplementary figures are available online. recognize on the cell surface the presence of microbe-associated molecular patterns (MAMPs) such as bacterial flagellin or fungus-derived chitin (Schwessinger and Zipfel 2008). A second class of mainly intracellular immune sensors, designated resistance $(\mathrm{R})$ proteins, recognizes either the structure or function of isolate-specific pathogen effectors that are delivered inside of host cells (Ellis et al. 2000). Effector-activated R proteins typically trigger a rapid host cell death response, called hypersensitive response, at sites of attempted ingress through a largely unknown molecular mechanism (Jones and Dangl 2006). Most known intracellular $\mathrm{R}$ proteins have a tripartite architecture consisting of $\mathrm{N}$-terminal coiled-coil (CC) or TOLL/interleukin-1 receptor (TIR) domains, a central nucleotide-binding (NB) site, and C-terminal leucine-rich repeats (LRR) (Shen and Schulze-Lefert 2007).

LRR domains of $\mathrm{R}$ proteins are thought to be major determinants of effector recognition (DeYoung and Innes 2006). This is supported by studies on several LRR domain-containing protein families, which are involved in ligand binding or protein-protein interactions such as the mouse Toll-like receptor TLR4 or Arabidopsis TIR1 ubiquitin ligase (Kim et al. 2007; Tan et al. 2007; Bella et al. 2008). A typical LRR consists of 20 to 29 residues that form a $\beta$-strand often followed by an $\alpha$ helix, which are arranged parallel to a common axis (Kajava et al. 1995). The conserved segment of 11 amino acids (LxxLxLxxN/CxL, in which $x$ stands for any residue and the $\mathrm{L}$ position can be occupied by any hydrophobic amino acid) of the $\beta$-strand/ $\beta$-turn motif lies on the concave face of the solenoid protein structure (Kobe and Kajava 2001). The leucine or related residues of the LRR motif point inward and build a hydrophobic core that gives a lateral stabilization to the repeat architecture, as deduced from solved crystal structures. The convex face of the LRR is often formed by an $\alpha$-helix (Kobe and Kajava 2001).

The crystal structures of LRR proteins revealed that the concave site, consisting of the $\beta$-strand motif and the adjacent turns, are the main site of protein interaction and ligand binding (Bella et al. 2008). Several studies in plants showed that residues of the LxxLxLxx $\beta$-strand motif are under stronger positive selection than other parts of the proteins, consistent with the hypothesis that this region is experiencing diversifying selection (Parniske et al. 1997; Botella et al. 1998; McDowell et al. 1998; Meyers et al. 1998; Ellis et al. 1999; Leckie et al. 1999; Noel et al. 1999; Mondragon-Palomino et al. 2002; Caicedo and Schaal 2004; Rose et al. 2004; Dodds et al. 2006; Yahiaoui et al. 2006; Dunning et al. 2007). Diversifying selection in the LRR domain has been reported for intracellular $\mathrm{CC}$ / 
TIR-NB-LRR R proteins encoded by allelic variants of Arabidopsis RPP13, flax $L$, and wheat Pm3 because nonsynonymous substitutions are overrepresented compared with changes in synonymous sites (Ellis et al. 1999; Rose et al. 2004; Yahiaoui et al. 2006). However, diversifying selection was also observed on the TIR-encoding region of flax $L$ (Luck et al. 2000), supporting previous findings that, for some $L$ proteins, resistance specificity is solely determined by the TIR domain (Ellis et al. 1999). Diversifying selection has also been detected in the flax rust AvrL567 and downy mildew ATR13 loci whose products are recognized by a subset of flax L and by Arabidopsis RPP13 proteins, respectively (Allen et al. 2004, 2008; Dodds et al. 2004). The structures of two AvrL567 effectors, each recognized by complementary flax L proteins, are very similar, with polymorphic residues located on their surface (Wang et al. 2007). Direct interactions were detected in yeast two-hybrid experiments between corresponding pairs of AvrL567 and L (Dodds et al. 2006). Together, these studies led to the proposal that direct binding or recognition of non-self structures by intracellular CC/TIR-NB-LRR $\mathrm{R}$ proteins is one molecular mechanism that governs the co-evolution of plant-microbe interactions, resulting in diversifying selection at corresponding $R$ and avirulence (AVR) loci (Wang et al. 2007).

Resistance conferred by barley Mla to Blumeria graminis $\mathrm{f}$. sp. hordei isolates might serve as further test case to investigate the pattern of selective forces that drive the generation of an allelic series of resistance specificities. Systematic genetic analysis of disease resistance in Hordeum vulgare subsp. vulgare to $B$. graminis f. sp. horde $i$ isolates revealed more than 30 Mla race-specific resistance specificities (Jorgensen 1994; Dheeranupattana 1995; Kintzios et al. 1995). Although other powdery mildew $R$ loci have been identified and mapped on all seven barley chromosomes, only Mla on chromosome $1 \mathrm{H}$ has been subjected to extreme functional diversification, encoding by far the largest number of $R$ genes to B. graminis $\mathrm{f}$. sp. hordei (Jorgensen 1994). A 265-kb contiguous DNA sequence spanning the Mla locus in cv. Morex identified eight $R$ gene homologs $(R G H)$, all belonging to the CC-NB-LRR class. These define three highly divergent families with $<43 \%$ amino acid sequence similarity between families and 78 to $100 \%$ similarity within families ( $R G H 1, R G H 2$, and $R G H 3$ ) (Wei et al. 2002). Six previously isolated Mla resistance specificities (Mla1, Mla6, Mla7, Mla10, Mla12, and Mla13) revealed that the encoded CC-NB-LRR-type proteins belong to a single subfamily sharing more than $90 \%$ sequence identity (Halterman et al. 2001, 2003; Zhou et al. 2001; Shen et al. 2003; Halterman and Wise 2004). These validated Mla resistance specificities are most closely related to $R G H 1 b c d$, a truncated and nonfunctional $R G H 1$ family member in cv. Morex, which lacks an Mla resistance specificity. These results and the presence of an (AT) microsatellite in intron 3 in all six functionally validated Mla $R$ genes but absence of the microsatellite in all presently available Mla RGH have led to the hypothesis that Mla powdery mildew resistance specificities represent allelic variants (Shen et al. 2003).

Two B. graminis f. sp. hordei effectors, $A V R_{A 10}$ and $A V R_{K 1}$, have been isolated using a map-based cloning approach (Ridout et al. 2006). These two powdery mildew effectors lack secretion signals and are members of a large gene family that is absent in other known Ascomycete genomes. The gene product of $A V R_{A 10}$ is recognized by MLA10 and the protein encoded by $A V R_{K l}$ is detected by the $R$ gene product of $M l k 1$, which maps approximately 5 centimorgans from Mla.

Here, we employed a two-step polymerase chain reaction (PCR) protocol to isolate 23 candidate MLA cDNAs from leaf RNA of barley accessions previously reported to harbor different Mla resistance specificities. A transient gene-expression assay in single leaf epidermal cells was subsequently used to measure the disease resistance activity of the candidate MLA cDNAs in response to two tested powdery mildew isolates. Resistance activity was detected for 13 candidate cDNAs that belong to the same CC-NB-LRR subfamily as the six previously described Mla $R$ gene products. The large number of validated and candidate MLA cDNAs provided, for the first time, the basis for an in-depth molecular diversity analysis. This revealed a gradient of increasing diversity toward the $\mathrm{C}$ terminus and uncovered a remarkable clustering of positive selection sites in the LRR domain.

\section{RESULTS}

\section{Diversity of infection phenotypes in barley cultivars containing different Mla resistance specificities.}

We aimed to explore the extent of sequence variation at Mla more widely by surveying 25 barley accessions that contain different Mla resistance specificities, as inferred from differential resistance responses to a collection of $B$. graminis f. $\mathrm{sp}$. hordei isolates and genetic linkage to this disease resistance locus on barley chromosome 1H (Table 1) (Jorgensen 1994; Dheeranupattana 1995; Kintzios et al. 1995). We also included six accessions that contain previously isolated Mla resistance specificities (Mla1, Mla6, Mla7, Mla10, Mla12, and Mla13) and 12 lines for which the presence or absence of a novel Mla resistance allele could not be unequivocally resolved (Table 1) (Jorgensen 1993, 1994). Many of the previously used powdery mildew isolates are no longer available. Therefore, we tested these barley accessions for differential infection phenotypes to two powdery mildew isolates, designated "A6" and "K1", each harboring a diverse subset of $A V R_{A}$ effector genes that are known to recognize different Mla resistance specificities (discussed below) (Bieri et al. 2004). Barley leaves were inoculated with fungal conidiospores and examined after 7 days for disease resistance against the two isolates. The observed host responses were classified into five macroscopic classes of infection types (IT) consisting of i) full immunity without detectable fungal growth, ii) barely detectable fungal growth typically surrounded by necrotic patches, iii) occasional fungal growth surrounded by necrotic patches, iv) extensive fungal growth and sporulation with few necrotic patches, and v) profuse fungal growth and sporulation without detectable necrotic areas (Table 1). The survey revealed isolate-specific IT (IT differing between A6 and K1 isolates on a particular line by at least two classes) (Table 1) in 14 of the 43 tested accessions. Growth of both fungal strains was severely restricted in 15 accessions (IT ii or lower) (Table 1).

\section{A cDNA-based PCR approach to isolate MLA cDNAs.}

We developed a cDNA-based PCR approach to isolate candidate MLA cDNAs. By this means, we excluded the isolation of potentially nonexpressed Mla homologs from the barley genome. A similar cDNA approach was used before to isolate Mla 7 and Mla10 (Halterman and Wise 2004). Among the six previously isolated Mla $R$ genes, the $3^{\prime}$ region encoding the LRR domain is diverse and contains interspersed short stretches of conserved sequences. In contrast, the $5^{\prime}$ region, including the $5^{\prime}$ untranslated region (UTR), and the sequence encoding the CC domain is well conserved throughout its length. This sequence conservation or variation pattern instigated the development of a two-step protocol to isolate candidate MLA cDNAs. First, PCR primers were designed from short conserved parts in the $3^{\prime}$ region encoding the LRR for 3'-rapid amplification of cDNA ends (RACE), typically resulting in approximately 700 bp fragments. If this $3^{\prime}$-RACE did not produce amplicons, we employed a 3' UTR PCR using primers in conserved stretches 
upstream and downstream of the stop codon. After sequencing of the amplicons, the sequence information was used in a second step to design a specific PCR downstream of the stop codon to amplify the complete coding region of candidate MLA cDNAs. Two specific primers within the 5' UTR were then designed and used to amplify the entire approximately 3.0-kb-long fragment of 19 candidate MLA cDNAs. Of these, 15 were isolated from barley accessions believed to harbor different Mla resistance specificities, and the cDNAs were named accordingly (Jorgensen 1994). Four additional candidate MLA cDNAs were obtained using a 5' UTR primer derived from a Mla homolog in $H$. chilense, designated
HcMlal. Collectively, these experiments resulted in the isolation of 23 candidate MLA cDNAs whose complete DNA sequences were determined (Table 1). Out of a total of 37 accessions that were molecularly inspected for the first time, we failed to obtain cDNA amplicons from three lines containing Mla17, Mla26, or Mla29 (Jahoor and Fischbeck 1987, 1993; Kintzios et al. 1995). This might be due to nucleotide polymorphisms at PCR primer-annealing sites in the corresponding MLA cDNAs.

We recovered five candidate MLA cDNAs from accessions for which it was previously unclear whether race-specific immunity is conferred by the Mla or a different $R$ locus on chromo-

Table 1. Barley cultivars used for the isolation of candidate and validated MLA cDNAs and their infection phenotypes to powdery mildew isolates A6 and K1

\begin{tabular}{|c|c|c|c|c|c|c|}
\hline \multicolumn{2}{|l|}{ Barley cultivars } & \multicolumn{2}{|c|}{ Mla resistance specificities } & \multicolumn{2}{|c|}{$\begin{array}{c}\text { Scored infection } \\
\text { phenotypes }^{\text {a }}\end{array}$} & \multirow[b]{2}{*}{ Reference } \\
\hline Name & Identifier & Proposed specificities & cDNA identifier & A6 & K1 & \\
\hline Ingrid isogenic (Black Russian, Mla2) & IGV 3-002 & 2 & $2 *$ & iv & iii & This work \\
\hline Ingrid isogenic (Ricardo, Mla3) & IGV 3-003 & 3 & $3 *$ & ii & ii & This work \\
\hline Gopal & PI 41162 & 5 & 7 & iii & iii & This work \\
\hline Golden Promise & PI 467829 & 8 & $8 *$ & $\mathrm{v}$ & $\mathrm{v}$ & This work \\
\hline Ingrid isogenic (Akka, Mla9) & IGV 3-009 & 9 & $9 *$ & ii & $\mathrm{v}$ & This work \\
\hline Ingrid isogenic (A222, Mla11) & IGV 3-011 & 11 & 8 & $\mathrm{v}$ & $\mathrm{V}$ & This work \\
\hline Ingrid isogenic (Franger, Mlal4) & IGV 3-015 & 14 & 6 & $\mathrm{i}$ & $\mathrm{v}$ & This work \\
\hline Long Glumes ${ }^{\mathrm{c}}$ & CIho 6168 & 15 & 7 & ii & $\mathrm{v}$ & This work \\
\hline Diamant $\times 1 B-54 B^{d}$ & $\ldots$ & 16 & $16-1$ & $\mathrm{i}$ & $\mathrm{i}$ & This work \\
\hline $\operatorname{RS} 170-47^{\mathrm{d}}$ & $\ldots$ & 17 & n.d. & ii & $\mathrm{i}$ & This work \\
\hline RS20-1 $\times$ Kiebitz B ${ }^{\mathrm{d}}$ & $\ldots$ & 18 & $18-1,18-2 *$ & $\mathrm{i}$ & $\mathrm{i}$ & This work \\
\hline Diamant $\times 1 B-86 B^{d}$ & $\ldots$ & 19 & $19-1$ & $\mathrm{i}$ & $\mathrm{i}$ & This work \\
\hline RS145-39 $\times$ Kiebitz $^{\mathrm{d}}$ & $\ldots$ & 20 & $25-1$ & $\mathrm{i}$ & $\mathrm{i}$ & This work \\
\hline Ingrid isogenic (Hordeum 1657, Mla22) & IGV 3-067 & 22 & $22 *$ & $\mathrm{v}$ & $\mathrm{i}$ & This work \\
\hline Ingrid isogenic (Hordeum 1402, Mla23) & IGV 3-066 & 23 & $23 *$ & iii & iii & This work \\
\hline Engledow India ${ }^{\mathrm{e}}$ & Clho 7555 & 24 & 13 & $\mathrm{i}$ & $\mathrm{i}$ & This work \\
\hline RS170-10 $\times$ Piccolo $A^{f}$ & $\ldots$ & 25 & $25-1$ & ii & ii & This work \\
\hline Diamant $\times 1 \mathrm{~B}-20^{\mathrm{f}}$ & $\ldots$ & 26 & n.d. & ii & $\mathrm{i}$ & This work \\
\hline RS1-8 $\times$ Piccolo $\mathrm{E}^{\mathrm{f}}$ & $\ldots$ & 27 & $27-1^{*}, 27-2^{*}$ & ii & $\mathrm{i}$ & This work \\
\hline Diamant $\times 1 \mathrm{~B}-151^{\mathrm{f}}$ & $\ldots$ & 28 & $28 *$ & $\mathrm{i}$ & $\mathrm{i}$ & This work \\
\hline $110-4 \times$ Sonja $^{\mathrm{g}}$ & $\ldots$ & 29 & n.d. & iv & ii & This work \\
\hline Nigrate & HOR 14775 & 30 & $30-1$ & iii & $\mathrm{v}$ & This work \\
\hline Turkey 290 & CIho 13646 & 31 & $31-1$ & $\mathrm{v}$ & $\mathrm{v}$ & This work \\
\hline $142-29 \times$ Dura $^{\mathrm{g}}$ & $\ldots$ & 32 & $32 *$ & $\mathrm{i}$ & $\mathrm{i}$ & This work \\
\hline RS70-29h & $\ldots$ & 34 & $34 *$ & $\mathrm{i}$ & $\mathrm{i}$ & This work \\
\hline Iso 1R Manchuria isogenic (Algerian, Mlal) & CIho 16137 & 1 & 1 & $\mathrm{v}$ & $\mathrm{i}$ & Zhou et al. 2001 \\
\hline Iso 20R Manchuria isogenic (Franger, Mlaø) & CIho 16151 & 6 & 6 & i & $\mathrm{v}$ & Halterman et al. 2001 \\
\hline Iso 10R Manchuria isogenic (Multan, Mla7) & CIho 16147 & 7 & 7 & iii & iv & Halterman et al. 2004 \\
\hline Iso 12R Manuchuria isogenic (Durani, Mla10) & CIho 16149 & 10 & 10 & $\mathrm{i}$ & $\mathrm{v}$ & Halterman et al. 2004 \\
\hline Ingrid isogenic (Emir, Mla12) & IGV 3-012 & 12 & 12 & ii & $\mathrm{V}$ & Shen et al. 2003 \\
\hline Manchuria isogenic (Rupee, Mla13) & CIho 16155 & 13 & 13 & $\mathrm{i}$ & $\mathrm{i}$ & Halterman et al. 2003 \\
\hline Sv. $57 / 510-44$ & CIho 14013 & MlTu2 & $35-1 *$ & $\mathrm{i}$ & $\mathrm{i}$ & This work \\
\hline Arlington Awnless & Clho 702 & Mly & $36-1$ & iii & $\mathrm{v}$ & This work \\
\hline Kairyobozu-mugi & CIho 11556 & Mlkb & $37-1$ & $\mathrm{v}$ & i & This work \\
\hline Nepal & PI 12709 & Mln & $38-1$ & iv & iv & This work \\
\hline Nigri Nudum & CIho 11549 & Mlnn & $39-1$ & iv & iv & This work \\
\hline Nakaizumi-Zairai & CIho 11561 & Mlk2 & 2 & iv & iii & This work \\
\hline Vogelsanger Gold & PI 406266 & Mlra & 6 & $\mathrm{i}$ & iv & This work \\
\hline Atlas & Clho 13824 & Mlat & 8 & $\mathrm{v}$ & iv & This work \\
\hline Magnif 105 & PI 337142 & $\mathrm{Mla}_{\mathrm{ma}}$ & 8 & iii & iv & This work \\
\hline 52 & PI 134257 & Mlci & 8 & $\mathrm{v}$ & $\mathrm{v}$ & This work \\
\hline Marco & PI 94877 & MlMa & 31 & iv & $\mathrm{v}$ & This work \\
\hline Russian 81 & Clho 11546 & Mlr81 & $39-1$ & iv & ii & This work \\
\hline
\end{tabular}

a Observed host responses against the powdery mildew isolates A6 and K1 were scored 7 days postinoculation and classified into five infection types (IT): i) full immunity without detectable fungal growth, ii) rarely detected fungal growth typically surrounded by necrotic patches, iii) occasional fungal growth surrounded by necrotic patches, iv) extensive fungal growth and sporulation with few necrotic patches, and v) profuse fungal growth and sporulation without detectable necrotic areas. Isolated candidate MLA cDNAs labeled with an asterisk (*) were confirmed to be active resistance genes with at least one of the fungal isolates A6 and K1 in the transient assay; n.d. = not detected.

${ }^{\mathrm{b}}$ It was suggested that the near-isogenic Ingrid line of Franger harbors the specificity Mla6 instead of Mla14 (Jorgensen 1994), which is confirmed by the isolation of Mla6 in this work.

${ }^{\mathrm{c}}$ It was believed that Long Glumes might harbor Mla7 instead of Mla15 (Kintzios et al. 1995), which is proven in this work by the isolation of Mla7.

d Jahoor and Fischbeck 1987.

e It was thought that Engledow India carries Mla13 instead of Mla24 (Jorgensen 1994), which is validated by the isolation of Mla13 in this work.

f Jahoor and Fischbeck 1993.

g Kintzios et al. 1995.

h Dheeranupattana 1995. 
some 1H (Jorgensen 1993, 1994). These cDNAs were recovered from accessions that do not belong to the original set of barley lines defining 34 Mla resistance specificities (Jorgensen 1994; Dheeranupattana 1995; Kintzios et al. 1995) but, nevertheless, show extensive sequence relatedness to known Mla $R$ genes; therefore, we named the corresponding genes Mla35-1, Mla361, Mla37-1, and Mla39-1 (Table 1). This nomenclature was adopted in analogy to previous studies (Zhou et al. 2001; Halterman et al. 2003) to denote that these genes might be nonfunctional or could be Mla homologs linked or unlinked to Mla. The MLA38-1 cDNA was isolated from the barley landrace Nepal and contains an in-frame stop codon that predicts a severely truncated protein of 232 amino acids (Fig. 1). Thus, we excluded this cDNA from further computational analysis (described below). Unexpectedly, from some barley accessions, we isolated cDNAs that were identical to known Mla resistance specificities. Cv. Gopal has been described to contain Mla5 (Jorgensen 1994) but the cDNA isolated from this accession is identical with the known MLA7 cDNA (Halterman and Wise 2004). Similarly, from the near-isogenic Mlall backcross line Ingrid (A222, Mla11), we isolated cDNAs that were identical with those identified in cv. Golden Promise containing Mla8. Finally, the MLA25-1 cDNA was independently isolated twice from accessions RS170-10 × Piccolo A and RS145-39 × Kiebitz B. The lat- ter accession was described to contain Mla20 (Table 1) (Jahoor and Fischbeck 1987). These discrepancies might result from accidental seed contamination or misinterpretation of previous infection experiments with $B$. graminis f. sp. hordei isolates.

\section{Two barley lines contain}

more than one candidate MLA cDNA.

Surprisingly, from two cultivars in each case, we isolated two different candidate MLA cDNAs. Cv. RS1-8 $\times$ Piccolo E was found to harbor candidate cDNAs that differ from each other only close to the $3^{\prime}$ end. In accordance with the nomenclature mentioned above, we designated these transcripts MLA27-1 and MLA27-2. MLA27-1 is six amino acid residues shorter than MLA27-2 and contains three polymorphic residues close to the C-terminus. In contrast, cv. RS20-1 $\times$ Kiebitz $\mathrm{B}$ was found to contain two transcripts with much sequence divergence throughout their lengths, predicting proteins sharing only $83 \%$ identity (Fig. 1). These cDNAs were designated MLA18-1 and MLA18-2. The detection of two candidate MLA cDNAs in Mla18 and Mla27 containing plants was unexpected because the Southern blot hybridization patterns of their DNA with a Mlal probe was similar to other lines from which only one cDNA species was isolated (described below). To exclude the possibility that the detection of two candidate cDNAs was

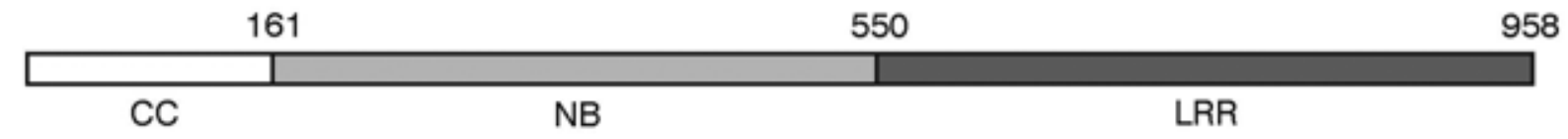

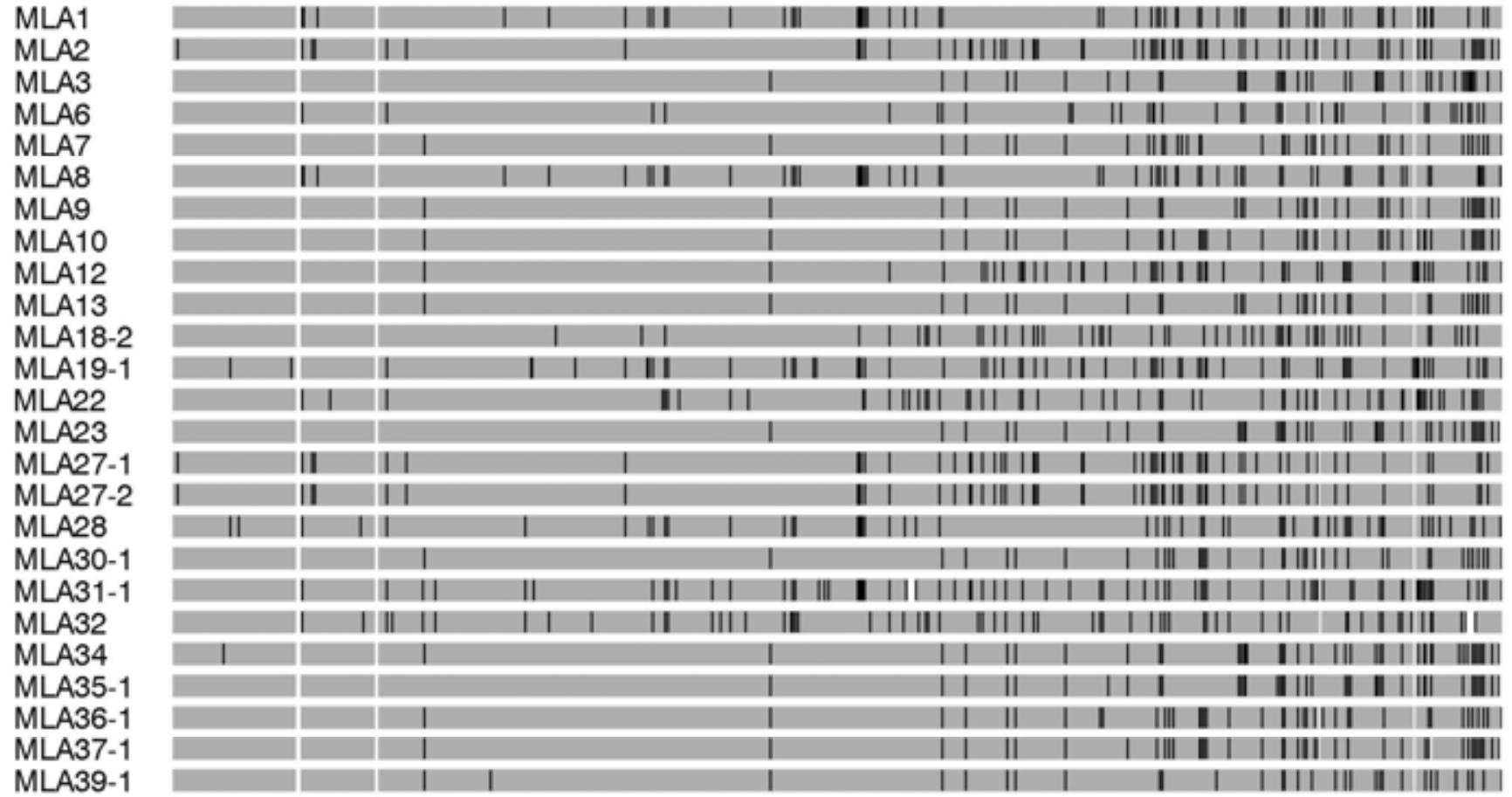

MLA16-1 || ||||||| |||||||||| || || | | | || | ||||||| || || || || || ||| ||| || || || | ||| || || || || || || ||| || || ||

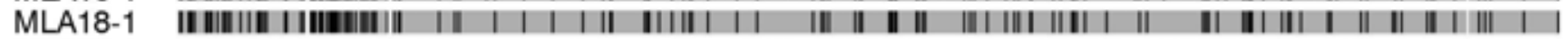
MLA25-1 || |||||||| || |||||||||| || || || ||| || |||||| || | ||||||| ||| || | |||||||| |||| | || || | || |||| MLA38-1 II||||||||| ||||||||||||| || ||

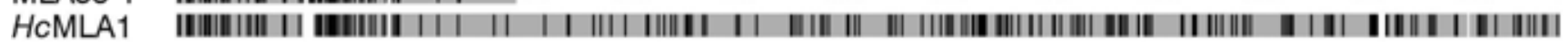

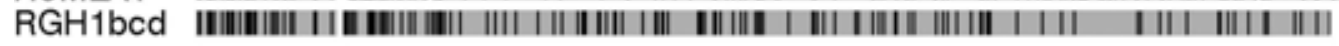

Fig. 1. Polymorphic sites cluster in the leucine-rich repeat of candidate and validated MLA resistance specificities. The proteins encoded by 29 validated and candidate MLA cDNAs are schematically represented by a consensus sequence (gray). Polymorphic residues are illustrated in black. The protein sequence deduced from Mla38-1 is truncated due to a stop codon at position 233. Two additional protein sequences encoded by Mla homologs were included: The 282-amino-acid-long sequence of RGH1bcd was obtained from barley cv. Morex (Wei et al. 2002) and HcMLA1 from Hordeum chilense. The three domains of MLA are indicated at the top. White: gap in the sequence alignment. 
the result of heterozygosity at the Mla locus, we self-fertilized single plants of the respective cultivars for three subsequent generations. Reisolation of the same two candidate cDNAs from selfed $S_{3}$ individuals (not shown) strongly suggests these are derived from Mla paralogs.

\section{Sequence analysis of cloned Mla alleles.}

Sequence alignment of gene products encoded by the candidate Mla cDNAs with the six known MLA proteins (MLA1, MLA6, MLA7, MLA10, MLA12, and MLA13) revealed a polymorphic LRR and, with four exceptions, a highly conserved CC-containing N-terminal region (Fig. 1). The six known MLA $\mathrm{R}$ proteins differ in the $\mathrm{N}$-terminal region (position 1 to 160) at only four residues. The first 46 residues of the $\mathrm{CC}$ domain are sufficient to interact with the transcription factors $H v$ WRKY 1 and $H v$ WRKY2 (Shen et al. 2007) and, within this stretch, 22 amino acids (residue 26 to 47 ) are predicted to adopt a CC structure (Zhou et al. 2001). This 22-amino-acid-long CC was detected in all 29 protein models using the program COILS (Lupas et al. 1991). Within the N-terminal 46 residues, only three polymorphisms were found among 25 of the total of 29 deduced proteins. Notably, the remaining four candidate cDNAs (MLA16-1, MLA18-1, MLA25-1, and MLA38-1), each encoding unusually polymorphic CC domains, are most similar to the deduced N-terminus of RGHIbcd in cv. Morex (Fig. 1) (Wei et al. 2002). Morex lacks a detectable Mla resistance specificity and $R G H 1 b c d$, encoding a truncated protein, is considered to be a nonfunctional Mla $R$ gene (Wei et al. 2002).
The full-length deduced proteins can be assigned to two subfamilies on the basis of neighbor-joining ( $\mathrm{NJ}$ ) distance tree analysis (regardless of whether truncated MLA38-1 and RGH1bcd are included or excluded from the calculation) (Fig. $2 \mathrm{~A}$ and B). Subfamily 1 consists of 25 members, including all six previously described MLA R proteins, and exhibits an overall sequence diversity of $8.8 \%$. Subfamily 2 includes only three members for which full-length sequences are available (MLA16-1, MLA18-1, and MLA25-1), with an overall sequence diversity of $7.4 \%$. Subfamily 2 also includes truncated MLA38-1 and RGH1bcd as well as the HcMLA1 homolog isolated from $H$. chilense. A comparison of a consensus sequence for subfamily 1 with the consensus sequence of subfamily 2 shows an overall sequence identity of $84.6 \%$, which is, expectedly, significantly lower than the overall sequence identity within each subfamily.

To assess the genomic diversity of the Mla locus in the examined barley cultivars and accessions, we performed a Southern blot analysis using a 501-bp Mlal probe, which encodes the C-terminal end of the NB domain (Fig. 3). Consistent with a previous report, four hybridization signals were detected in DNA from cv. Morex that correspond to the four closely related $\mathrm{RGHI}$ members at the Mla locus in this line, designated RGHla, RGHIbcd, RGHle, and RGHIf (Fig. 3) (Wei et al. 2002). As described by Wei and associates (2002), not all of these genes are transcribed. Although we detected in our diversity survey several distinct hybridization patterns between accessions, most accessions showed fewer and the remaining
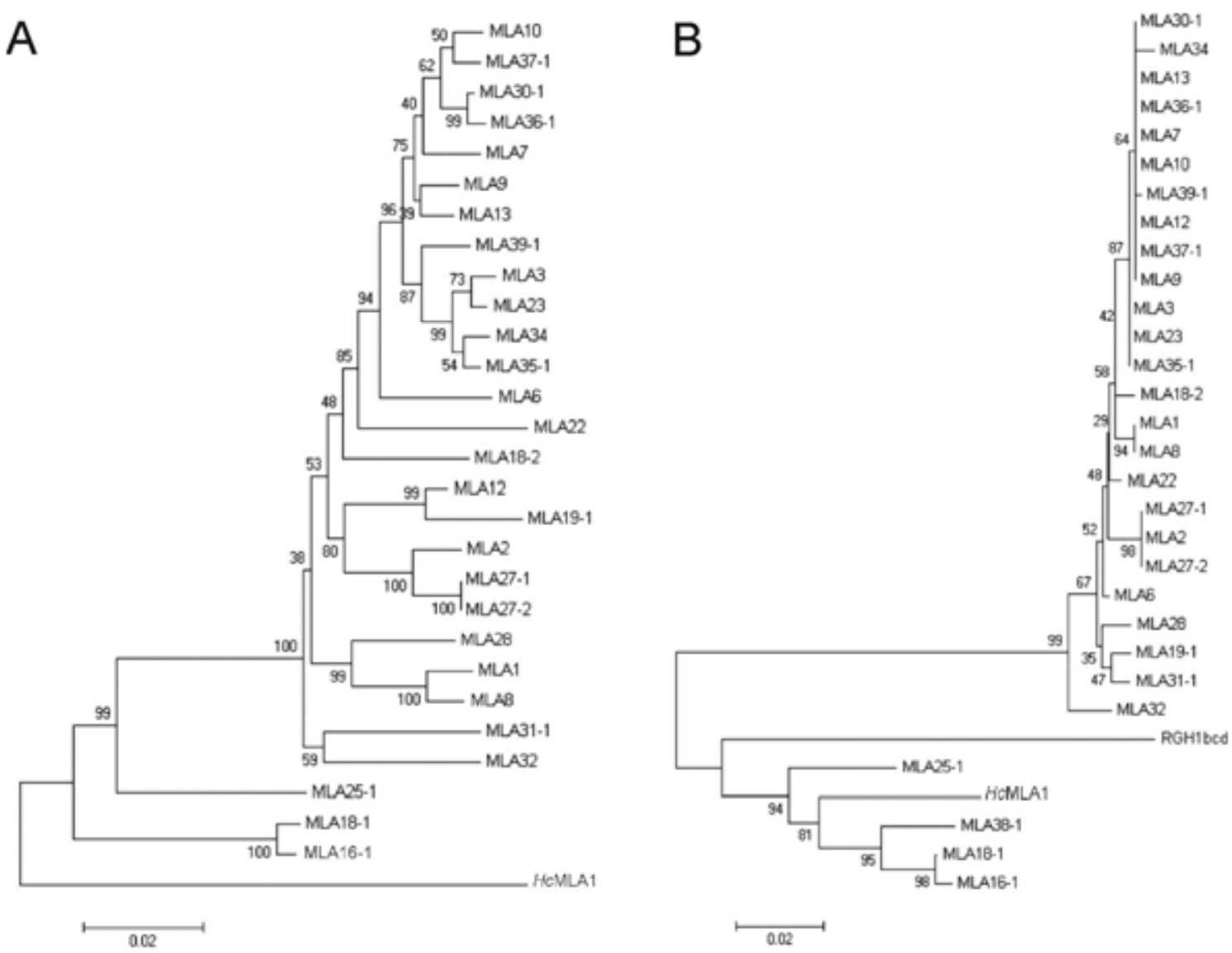

Fig. 2. Neighbor-joining (NJ) tree analysis of proteins encoded by validated and candidate MLA cDNAs. A, NJ unrooted tree of proteins encoded by 29 fulllength MLA cDNA sequences (note that Mla38-1 and RGH1bcd were omitted). B, NJ unrooted tree of proteins encoded by 31 MLA cDNA sequences. Note that the MLA38-1 protein is only 232 amino acids long. The protein encoded by the nonfunctional RGH1bcd from cv. Morex is truncated due to a stop codon at position 713 (Wei et al. 2002). Thus, the sequences were only compared until the nucleotide position corresponding to amino acid position 213 for the tree calculations. An MLA homolog, HcMLA1, was obtained from Hordeum chilense. All positions containing gaps and missing data were eliminated from the dataset (complete deletion option). The values on the branches indicate the percentage of 1,000 bootstrap replicates. 
lines a similar number (up to six) of hybridization signals compared with Morex (Fig. 3). This indicates limited variation in the number of Mla paralogs and lack of unusual paralog expansion in the examined germplasm.

\section{Functional analysis of candidate MLA cDNAs.}

We used a transient gene-expression assay to assess the disease resistance activity of the candidate MLA cDNAs following particle-mediated delivery of plasmid DNA in single barley leaf epidermal cells (Shen et al. 2003). Expression of the cDNAs is driven by the strong ubiquitin promoter and disease resistance was quantitatively scored as powdery mildew haustorium index (percent) in epidermal cells attacked by sporelings of the A6 or $\mathrm{K} 1$ isolates 2 days after conidiospore inoculation (Shen et al. 2003). The differential haustorium index detected upon the delivery of MLA1 or MLA6 cDNAs and inoculations with the A6 and $\mathrm{K} 1$ fungal strains served as susceptible and race-specific resistant controls (Fig. 4A and B). Candidate MLA cDNAs that conferred a reduced haustorium index compared with these susceptible controls upon challenge with at least one of the two strains are indicated in Figure 4A and B. Only two cDNAs, MLA9 and MLA22, showed a marked differential infection phenotype upon challenge with mildew isolates A6 or $\mathrm{K} 1$. This race-specific activity is consistent with the differential infection phenotypes seen in intact leaves of the Mla9- and Mla22-containing accessions (Table 1), indicating that the two candidate cDNAs encode authentic MLA resistance specificities.

Transient expression of 11 other cDNAs significantly restricted haustorium development (Fig. 4). Among these are
MLA27-1 and MLA27-2, indicating that cv. RS1-8 $\times$ Piccolo E, containing the paralogs Mla27-1 and MLA27-2, harbors two functional Mla genes.

Candidate cDNAs MLA3, MLA23, and MLA35-1 differ from each other by few polymorphic sites. MLA3 is six amino acids longer than MLA23 and differs by 13 residues in the $C$ terminus, whereas MLA35-1 differs from MLA23 by nine residues located in the LRR. Each of the candidate cDNAs conferred a similar haustorium index ranging from 50 to $70 \%$ upon inoculation with the $\mathrm{K} 1$ isolate, which is slightly but significantly lower compared with the control plasmid harboring MLA6 $(84 \%)$ (Fig. 4B).

Plants of cv. Golden Promise (Mla8) are fully susceptible to both A6 and K1 isolates (IT v) (Table 1). Unexpectedly, transient gene expression of the candidate MLA8 cDNA resulted in a moderate reduction of the haustorium index $(65 \%)$ in response to challenge with the $\mathrm{K} 1$ but not $\mathrm{A} 6$ isolate (Fig. 4). The protein encoded by this cDNA is identical with MLA1 up to residue 795 in the 10th LRR (Supplementary Fig. 1). Expression of the MLA1 cDNA drastically reduces the haustorium index to $26 \%$ in a K1-specific manner (Fig. 4). Thus, the differences between strong and weak resistance activities triggered by MLA1 and candidate MLA8 in the transient geneexpression assay must be determined by the C-terminal 164 residues of the LRR. A similar observation was made for the Mla2-containing isogenic line Ingrid, which is susceptible to isolates $\mathrm{K} 1$ and $\mathrm{A} 6$. When tested in the transient assay, the candidate Mla2 gene strongly reduced the haustorial index (Fig. 4). Interestingly, MLA2 and MLA27-1/2 share an identical protein sequence until position 804 . The interpretation of these

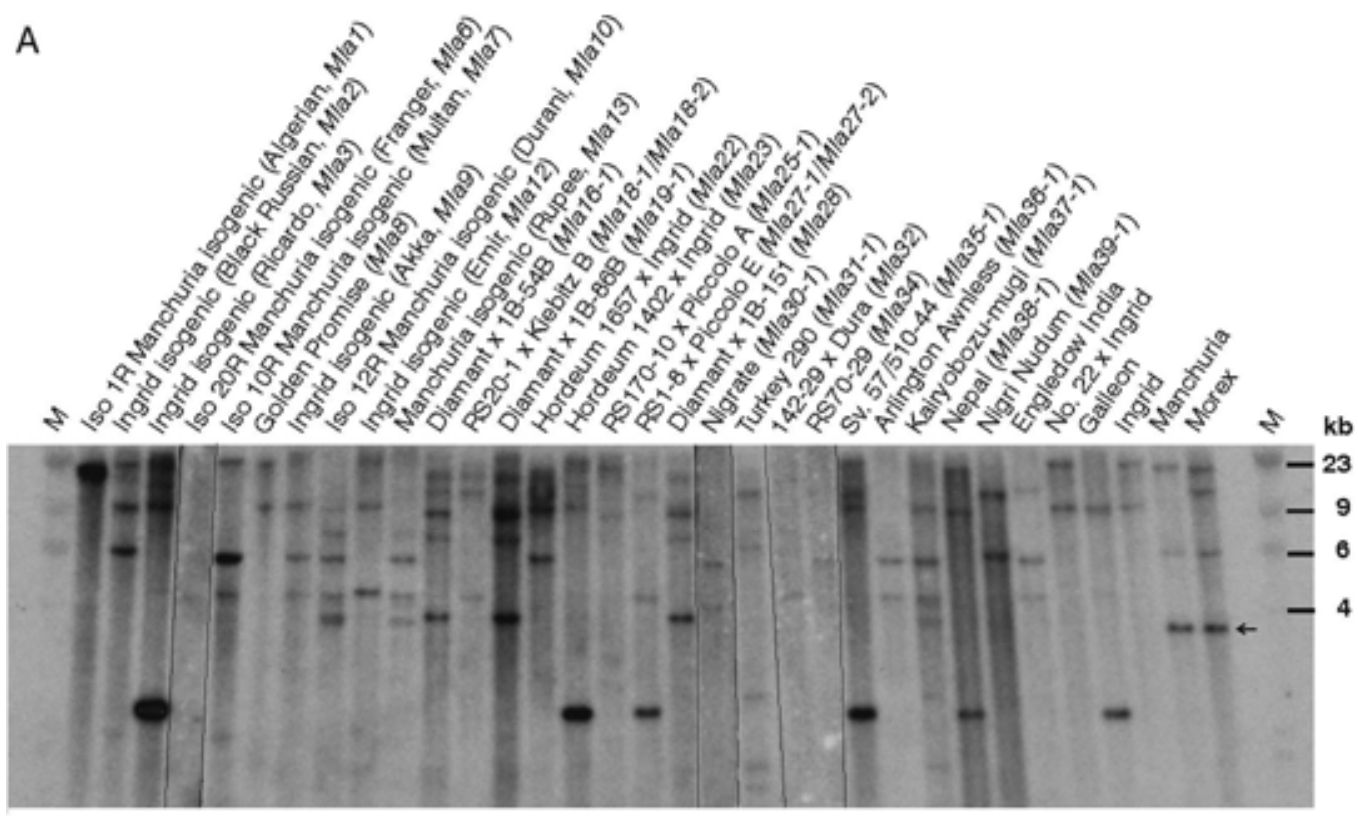

B

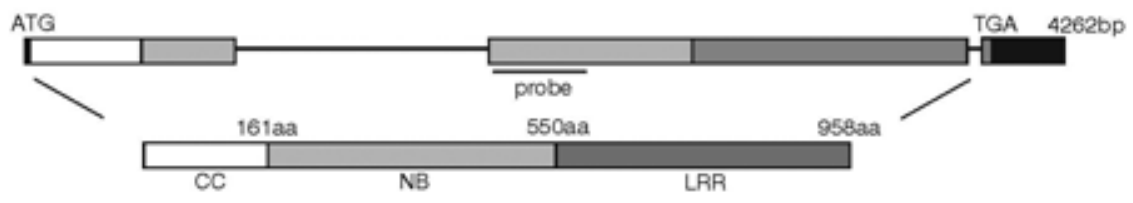

Fig. 3. Diversity survey of Mla homologs. A, Southern blot analysis. Genomic DNA was isolated from the indicated 29 barley accessions and cultivars from which the candidate and validated MLA cDNAs were isolated, and was digested with EcoRI. The autoradiography shown is composed of two independent Southern blot experiments with qualitatively identical results. The indicated 501-bp DNA fragment (depicted in B) was used as a probe and was amplified from the region encoding the NB domain of Mlal. For cv. Morex, four hybridization signals are visible. The lowest corresponds to RGH1bcd (arrow) and the other signals to the Mla homologs RGHla, RGHe, and RGHf. The truncated gene RGHIbcd is proposed to be a non-functional Mla allele (Wei et al. 2002). Most barley accessions show a hybridization pattern with fewer bands than Morex. M: size marker. B, Genomic region of Mlal (4262 bp) and the corresponding protein are depicted. The region amplified for the hybridization probe is indicated. 


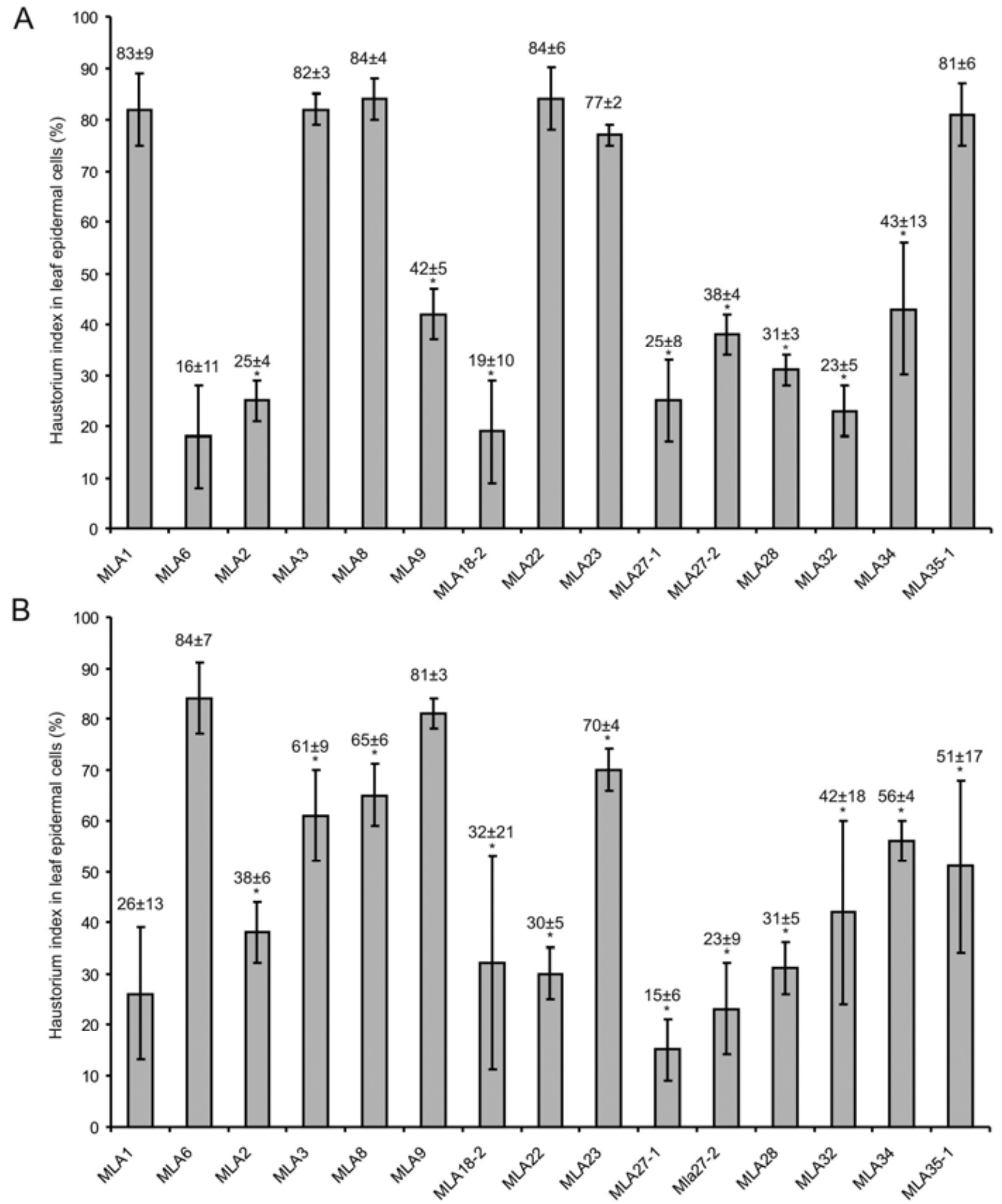

Fig. 4. Functional analysis of candidate MLA cDNAs by transient single-cell gene expression. Plasmid DNA containing the indicated MLA cDNAs and a $\beta$ glucuronidase (GUS) reporter were co-delivered into epidermal cells of barley leaves by particle bombardment. The leaves were incubated for $48 \mathrm{~h}$ after inoculation with powdery mildew conidiospores. GUS-stained single epidermal cells were then microscopically evaluated for the presence or absence of a fungal haustorium (haustorium index $=\%$ GUS-expressing epidermal cells attacked by a fungal sporeling that contain a haustorium). Data (including standard deviations) shown are based on the microscopic inspection of 50 to 100 interaction sites from at least four leaves and at least two independent biological replicates. MLA cDNAs labeled with an asterisk conferred a haustorium index that was different from the respective susceptible control (Student's $t$ test: $P<$ 0.05). A, Inoculation with Blumeria graminis f. sp. hordei isolate A6. MLA1 cDNA was used as a susceptible and MLA6 cDNA as a resistant control. B, Inoculation with B. graminis f. sp. horde $i$ isolate K1. MLA6 cDNA was used as a susceptible and MLA1 cDNA as a resistant control. Note that MLA18-2, MLA27-1, MLA27-2, MLA28, MLA32, and MLA34 restrict fungal growth of both isolates. 
data must consider that overexpression of the Mla alleles can alter the reaction kinetics of a late host response (Shen et al. 2003). It was shown for Mla12 that overexpression shifted the resistance response from post-haustorium resistance to an earlier termination of fungal growth (Shen et al. 2003). No discrepancy was found in resistance kinetics when the fast-reacting alleles Mlal and Mla6 were tested whose expression was driven by either the native $5^{\prime}$ sequences or by the ubiquitin promoter (Boyd et al. 1995; Shen et al. 2003). Thus, it seems that overexpression might affect the experimental outcome only in case of Mla genes that trigger a slow host response.

In total, 13 of 19 novel members of subfamily 1 but none of the members of subfamily 2 (Mla16-1, MLA18-1, MLA25-1, as well as MLA38-1) conferred disease resistance in the transient gene-expression assay (Fig. 4). Candidate cDNAs of subfamily 2 encode exceptionally polymorphic $\mathrm{N}$-terminal $\mathrm{CC}$
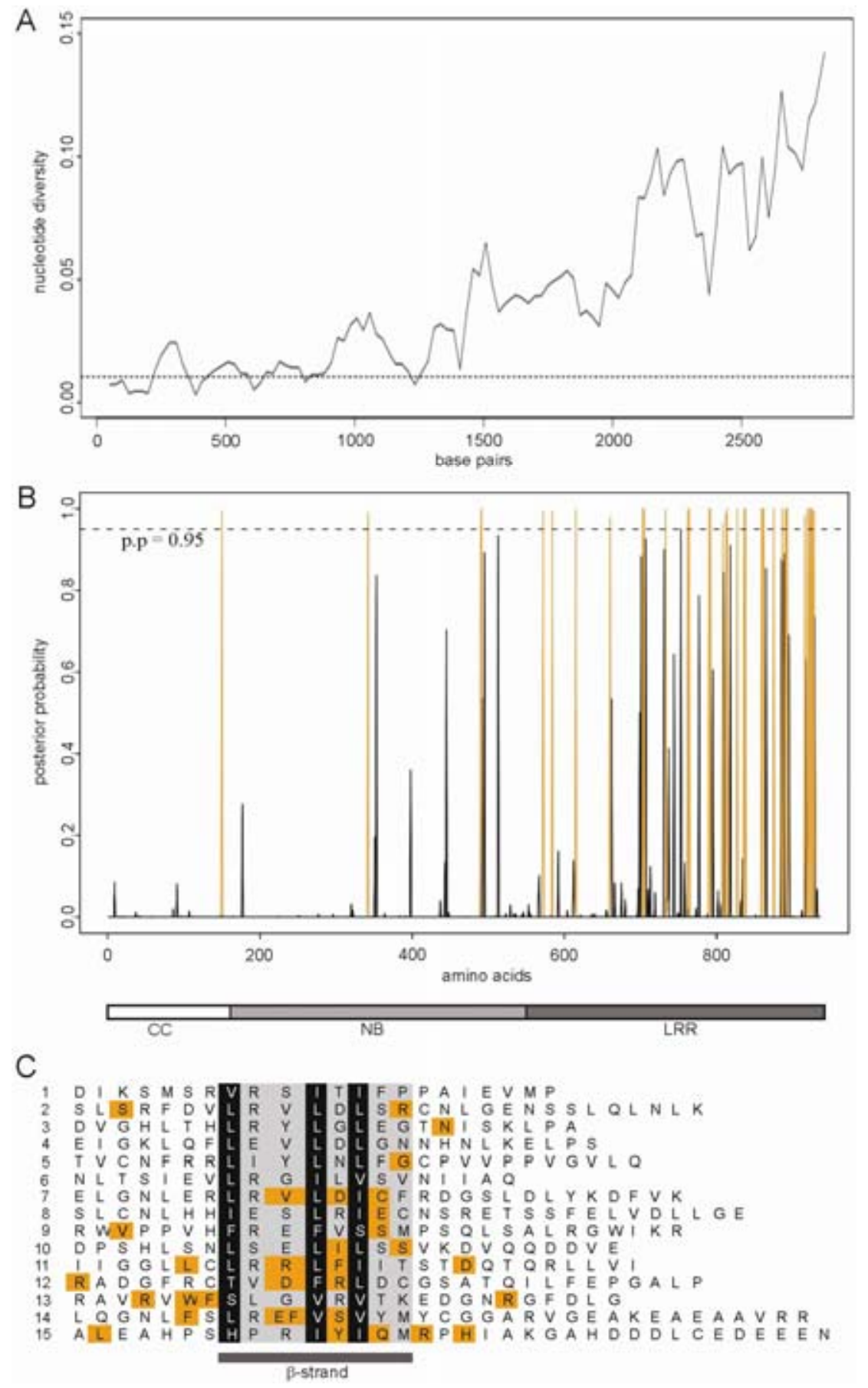

Fig. 5. Nucleotide diversity and positively selected sites in candidate and validated MLA cDNAs. A, Sliding window analysis of the nucleotide diversity ( $\pi$ ) for 25 candidate and validated MLA cDNAs. MLA16-1, MLA18-1, and MLA25-1 were omitted from the analysis due to their divergent coiled-coil domains and MLA38-1 due to a stop codon at position 332. B, Amino acid residues are judged to be under positive selection if they are above a posterior probability of 0.95 (indicated by a dotted line). C, Illustration of the 15 leucine-rich repeats (LRR) of MLA1 that are conserved in all 25 MLA sequences. The first LRR starts at position 555. The LxxLxLxx sites, which are proposed to form a short, solvent-exposed $\beta$-strand motif (Kajava et al. 1995), are indicated. Note that the 14th LRR is irregular with three instead of two x positions after the first L position. Black: hydrophobic core residue; gray: site of any amino acid termed $x$ in the LxxLxLxx motif. The 32 sites of positive selection are highlighted in orange. In all, 18 of 32 positively selected sites in the LRR domain lie directly at an x position in the solvent-exposed LxxLxLxx motif. All shown positions of positive selection are statistically significant (posterior probabilities $>0.95$ ) when looking at the set of 25 MLA sequences. 
domain-containing regions compared with other candidate or validated MLAs (Fig. 1). Each of these four N-terminal regions is most closely related to the $\mathrm{N}$ terminus encoded by the nonfunctional presumed Mla allele RGHlbcd in cv. Morex (Wei et al. 2002). The lack of resistance activity for cDNA MLA38-1 was expected due to a stop codon leading to a 232-amino-acidlong truncated protein form. We then tested two additional $B$. graminis f. sp. hordei isolates on the four corresponding barley accessions and observed, as with the A6 and K1 isolates, full resistance, with the exception of susceptibility on accession Nepal harboring Mla38-1 (not shown). None of MLA16-1, MLA18-1, or MLA25-1 cDNAs conferred disease resistance in transient gene-expression assays upon challenge with these two additionally tested $B$. graminis $\mathrm{f}$. sp. hordei isolates (not shown). Thus, we conclude that the resistance response in Mla16-1- and Mla25-containing plants is likely based on at least one active $R$ locus different from Mla. Because the Mla18-1-containing plants also harbor a subfamily 1 member, Mla18-2, which is functional (Fig. 4), the resistance in these plants could be conferred by Mla18-2 or another $R$ locus.

The apparent conservation of a subfamily of MLA homologs (comprising MLA16-1, MLA18-1, MLA25-1, truncated MLA38-1, and RGHbcd1, as well as HcMLA1) (Fig. 1) sharing a similar distinctive $\mathrm{N}$-terminal region and lacking detectable B. graminis f. sp. hordei resistance activity could point to neofunctionalization. For this reason, we have excluded members of this subfamily from most of the molecular diversity analysis described below. A summary of the phylogenetic and functional analysis of the new Mla genes is given in Supplementary Table 2 .

\section{Identification of previously overlooked MLA LRR.}

The Mlal sequence was used to deduce a prototypical MLA protein of 958 amino acids containing, within its $\mathrm{N}$-terminal region (residue 1 to 160), the $\mathrm{CC}$ domain, a central NB domain (161 to 549), and C-terminal LRR (550 to 958) (Zhou et al. 2001; Halterman and Wise 2004). The alignment of the novel candidate and previously validated MLA sequences described in this study (Fig. 1) enabled us to greatly improve the detection of structural motifs. Specifically, we detected the presence of four additional LRR, which increases the total repeat number to 15 . These include the 1st LRR at position 557 (numbers refer to MLA1) and three additional imperfect LRR at the Cterminal end (13th to 15 th LRR).

The latter repeats, including the 12th LRR, are considered imperfect because of the lack of hydrophobic residues at the leucine positions in the LxxLxLxx motif (Kobe and Kajava 2001) in some candidate MLA sequences. The 14th LRR has three variable positions instead of two after the first leucine of the LxxLxLxx motif. The existence of these additional MLA LRR was independently supported by the secondary structure prediction programs PSIPRED (Bryson et al. 2005) and SCRATCH (Cheng et al. 2005), each predicting a short $\beta$ sheet for the respective LxxLxLxx motifs. Of further note, the highly conserved acidic motif (G/D)A(H/Q)DDDL(C/M) at the very $\mathrm{C}$ terminus of the deduced proteins appears to be an additional signature of MLA homologs.

\section{Positively selected sites cluster in the LRR domain.}

All 25 candidate and validated MLA cDNA sequences of subfamily 1 were used to calculate the nucleotide diversity ( $\pi=$ 0.043 ) and nucleotide polymorphism $(\theta=0.045)$ (Fig. 5A; Table 2). Because our sampling strategy was not random, in that we specifically analyzed Mla sequences defined as active resistance genes in earlier studies, the values are not comparable with previous population genetic surveys of barley (Saisho and Purugganan 2007). Here, we use nucleotide diversity solely to compare the diversity among different domains within Mla. The region encoding the LRR was highly variable among all studied cDNAs, with nucleotide diversity increasing in a gradient toward the $\mathrm{C}$ terminus (Fig. 5A). Not only nonsynonymous $\pi$ but also synonymous $\pi$ was elevated in the LRR domain (Table 2). After the seventh LRR, several sites were found that are occupied by five or six different amino acids. The LRR domain had the highest nucleotide diversity along the Mla gene with a $\pi$ value of 0.074 (Table 2). These results are consistent with the clustering of positively selected sites in the LRR domain (described below).

In order to assay sequence diversity, we analyzed the pattern of amino acid evolution. First, we calculated the ratio of nonsynonymous $\left(d_{\mathrm{N}}\right)$ and synonymous $\left(d_{\mathrm{S}}\right)$ nucleotide substitutions among Mla sequences $\left(d_{\mathrm{N}} / d_{\mathrm{S}}\right.$ ratio, or $\left.\pi_{\mathrm{non}} / \pi_{\mathrm{syn}}\right)$. The values were calculated for the entire coding region and separately for regions encoding the $\mathrm{N}$-terminal CC-containing part, the NB domain, and the LRR domain (Table 2). The $d_{\mathrm{N}} / d_{\mathrm{S}}$ ratio of the entire coding region was 0.544 , and was higher in the part encoding the LRR $\left(d_{N} / d_{\mathrm{S}}=0.720\right)$.

Selection can be highly localized within genes and, thus, the $d_{N} / d_{\mathrm{S}}$ ratio is often not adequate to detect positive selection. We used PAML version 4 to estimate $d_{\mathrm{N}} / d_{\mathrm{S}}$ ratios, or $\omega$, at each position of the sequence alignment (Yang 2007). We compared values of likelihood ratios for several nested models of codon substitutions (discussed below). In all these analyses, the models that allow $d_{N} / d_{\mathrm{S}}>1$ fitted the data significantly better than the models where $d_{N} / d_{\mathrm{S}}>1$ is not permitted. This indicates that several nucleotide positions of the 25 candidate and validated MLA variants are under positive selection. The analysis was also performed for three sequence subsets. One subset contained $19 \mathrm{cDNAs}$ that conferred resistance activity to the powdery mildew fungus (Figure 4 and previously published Mla resistance specificities). A second subset contained both candidate and validated MLA cDNAs (25 variants) of subfamily 1 . These calculations gave similar results, indicating that the choice of subsets has only a minor effect on the overall outcome. We conducted these analyses based on NJ and maximum parsimonious (MP) trees and confirmed no significant differences, indicating that these results are robust to the phylogenetic trees on which PAML analyses are based (Supple-

Table 2. Nucleotide polymorphism and divergence of 25 candidate and validated MLA cDNAs ${ }^{\mathrm{a}}$

\begin{tabular}{|c|c|c|c|c|}
\hline Parameter & Entire gene & CC domain & NB domain & LRR domain \\
\hline Number of sites & 2,850 & 453 & 1,194 & 1,203 \\
\hline Segregating sites & 478 & 27 & 131 & 320 \\
\hline$\theta_{\mathrm{W}}$ & 0.045 & 0.016 & 0.029 & 0.072 \\
\hline$\pi($ total $)$ & 0.043 & 0.011 & 0.024 & 0.074 \\
\hline$\pi_{\text {syn }}$ & 0.0644 & 0.0209 & 0.0513 & 0.092 \\
\hline$\pi_{\text {non }}$ & 0.0364 & 0.0078 & 0.0164 & 0.0686 \\
\hline Intraspecific $d_{\mathrm{N}} / d_{\mathrm{S}}\left(\pi_{\mathrm{non}} / \pi_{\mathrm{syn}}\right)$ & 0.544 & 0.269 & 0.316 & 0.720 \\
\hline Tajima's $D^{\mathrm{b}}$ & -1.999 & -1.196 & -0.746 & 0.120 \\
\hline
\end{tabular}

\footnotetext{
${ }^{a} \mathrm{CC}=$ coiled-coil, $\mathrm{NB}=$ nucleotide binding, and LRR = leucine-rich repeat.
}

b Total numbers of mutations were used for the calculation of Tajima's $D$ value. 
mentary Tables 3 and 4). Similar results were also obtained when we inspected a third sequence subset comprising only the nine candidate MLA cDNAs for which a resistance response to isolates A6 and K1 was undetectable (Mla19-1, Mla30-1, Mla31-1, Mla36-1, Mla37-1, and Mla39-1) (data not shown).

When all 25 candidate and validated MLA cDNA sequences were included, 34 positive selection sites with a posterior probability (p.p.) >0.95 were identified (Fig. 5B). Of these, only one site was found in the $\mathrm{CC}$ region (at the $\mathrm{C}$-terminal end near the hhGRExe motif of the NB domain) and one site in the NB domain within the so-called RNBS-C motif (Van Ooijen et al. 2008). A remarkable number of 32 positively selected sites were found in the LRR domain. Of these, 18 sites affect residues in the LxxLxLxx motif on the predicted concave face of the LRR domain and most of the remaining ones were on either side adjacent to this motif ( $\chi^{2}$ test, $P<1.36 \times 10^{-90}$ ) (Fig. 5C). It is postulated that the solvent-exposed concave site is critical for the recognition of a putative interaction partner (Ellis et al. 2007).

The PAML method may overestimate the prevalence of positive selection when there is gene conversion. The program Geneconv (Sawyer et al. 1999) identified 96 significant $(P<$ $0.05)$ putative gene conversion or recombination tracks in 25 candidate and validated MLA cDNA sequences compared with each other (Supplementary Fig. 2). Gene conversion was detected mostly in the region containing the CC domain, the NB domain, and the first four LRR until position 2,100, with a few exceptions (numbering refers to MLA1 cDNA). This suggests that the LRR mostly experienced a different evolutionary history compared with the first part of Mla. Based on this result, we performed a PAML analysis specifically of the region from position 2,101 to the end of the gene. The obtained data provided the same significant fit for models that allow $d_{N} / d_{\mathrm{S}}>1$ as obtained for the entire Mla gene and corroborated that a large number of amino acids in the LRR is under positive selection. Positive selection sites were significantly localized at the LxxLxLxx motif on the concave face of the LRR ( $\chi^{2}$ test, $P<$ $\left.1.94 \times 10^{-43}\right)$.

\section{DISCUSSION}

Previous genetic experiments failed to distinguish whether different Mla resistance specificities represent closely linked genes or alleles (Jorgensen and Moseman 1972; Giese et al. 1981; Wise and Ellingboe 1985). The lack of barley lines harboring two Mla specificities, the presence of an (AT) $)_{n}$ microsatellite marker in intron 3 of six known Mla R genes, and their exceptional sequence similarity suggested that these represent allelic variants (Wei et al. 2002; Bieri et al. 2004). Here, we have obtained for the first time evidence for the existence of two functional Mla genes in the same barley accession, line RS1-8 $\times$ Piccolo E. Both genes are functionally identical. This indicates the presence of Mla gene duplications in some barley genotypes, making the definition of allelism complex. However, the identification of one expressed member of subfamily 1 in all other tested accessions strongly suggests that these are typically present as single-copy genes or that only one gene copy is expressed. Closely related copies of Mla are present in most lines as indicated by Southern analysis but these are not necessarily expressed (Wei et al. 2002). Conclusive evidence of the number and relatedness of active Mla gene copies will require contiguous genomic sequences of the Mla locus from multiple accessions. Within the limited resolution of our Southern analysis, we found no evidence for unusual copy number expansion, and all tested lines appear to contain at least one RGH1 family member. Taken together, we consider it likely that most of the novel members of subfamily 1 represent further allelic variants of the previously described Mla $R$ alleles.
Cv. Morex lacks a known Mla resistance specificity. The DNA sequence of a 261-kb BAC contig that spans the Mla locus in Morex contains eight $R G H$, all belonging to the CCNB-LRR class, that define three dissimilar families with $<43 \%$ amino acid sequence similarity between families and 78 to $100 \%$ similarity within families. Within this contig, RGHlbcd shares the highest similarity with functional Mla resistance specificities and contains a 29-bp deletion in the LRR. For this reason, $R G H 1 b c d$ has been proposed to represent a nonfunctional Mla allele (Wei et al. 2002). Our study shows that RGH1bcd is a member of subfamily 2, which also includes truncated MLA38-1. The sequence diversification within subfamily 2 , including three members with full-length sequences (MLA16-1, MLA18-1, and MLA25-1) and its obvious divergence from subfamily 1 , points to a potential subfamily-specific functionalization. If so, then the 261-kb BAC contig spanning the MLA locus in Morex lacks members of subfamily 1. Thus, the lack of an Mla resistance specificity in this cultivar might result from the deletion of an unknown Mla gene belonging to subfamily 1 .

In addition to the alleles Mla14, Mla15, and Mla24, which are unlikely to exist based on our analysis, a few additional discrepancies between lines previously described to contain different Mla genes were revealed. We isolated the known MLA7 cDNA (Halterman and Wise 2004) from cv. Gopal, thought to contain Mla5. Similarly, the candidate MLA8 cDNA derived from cv. Golden Promise was independently isolated from another cultivar presumed to harbor Mla11. This cDNA was independently identified in three other accessions for which a powdery mildew resistance specificity had been assigned to chromosome $1 \mathrm{H}$ but linkage to Mla was unknown (Table 1) (Jorgensen 1993). Thus, we conclude that the candidate MLA8 cDNA is derived from the proposed Mla 8 that is also present in the three accessions containing uncharacterized powdery mildew $R$ specificities on chromosome 1H. The proposed MLA8 is identical with MLA1 up to the 10th LRR, suggesting that one of them is the product of a recent recombination event between two Mla $R$ specificities. Strong evidence that LRR 10 to 15 can be sufficient to determine recognition specificity was demonstrated in vitro by the generation and subsequent in vivo analysis of MLA chimeras (Shen et al. 2003). An LRR chimera that contains MLA1 sequences, including the ninth LRR and MLA6-derived LRR 10 to 15, exhibits MLA6-recognition specificity. Thus, it is conceivable that the MLA8 LRR 10 to 15 determine the MLA8-recognition specificity.

The large number of novel candidate and validated MLA sequences described in this study has greatly improved the detection of cryptic sequence motifs in the LRR. Both motif search and secondary structure prediction programs identified four additional previously undetected LRR, increasing the total number of repeats to 15 in the LRR domain. The total number of LRR is of relevance for an LRR domain-containing protein because it is one parameter determining the inner (concave) space of the LRR solenoid available for ligand binding (Bella et al. 2008). The newly identified LRR were previously overlooked (Halterman et al. 2001; Zhou et al. 2001; Halterman and Wise 2004) because individual LRR can tolerate one or more substitutions of amino acids in the consensus sequence to nonhydrophobic or even charged ones (Bella et al. 2008). A large number of gene variants are critical for accurate manual annotation of such imperfect LRR within a protein subfamily. All 15 predicted MLA LRR-type $\beta$ strands can be characterized by the consensus sequence $\Phi \mathrm{xx} \Omega \mathrm{x} \Omega \mathrm{xx}(\Omega$ denotes noncharged amino acids and $\Phi$ denotes hydrophobic amino acids including L or I or V or F or S). Only the 14th LRR contains one additional amino acid in this consensus sequence $(\Phi \mathrm{xxx} \Omega \mathrm{x} \Omega \mathrm{xx})$ (Fig. 5C). Importantly, the almost complete length conservation 
of individual LRR among MLA variants, but the considerable length variation between the 15 LRR (ranging from 20 to 35 residues) points to a marked structural constraint of the overall domain for MLA function.

We have shown here that, with two exceptions, all positive selection sites reside within the LRR domain. Out of a total of 32 positive selection sites in the Mla LRR domain, 18 reside in the encoded $\Phi \mathrm{xx} \Omega \mathrm{x} \Omega \mathrm{xx}$ consensus sequence of the LRR. All of these 18 sites represent solvent-exposed residues of the predicted $\beta$-sheet lining on the concave surface of the LRR domain. This is reminiscent of data described for flax L, Arabidopsis $R P P 13$, and wheat $P m 3$, for which positive selection sites were found mostly in the presumed solvent-exposed residues of individual LRR (Ellis et al. 1999; Rose et al. 2004; Yahiaoui et al. 2006). The remaining 14 positive selection sites in the Mla LRR domain are found on either side at a maximal distance of six residues away from the $\Phi \mathrm{xx} \Omega \mathrm{x} \Omega \mathrm{xx}$ consensus sequence. LRR containing more than two positive selection sites (ranging between three and five) were found only in the C-terminal LRR 7 and 11 to 15 . Because changes in one or two solvent-exposed residues on the concave side of LRR domains can be sufficient to increase or decrease ligand-binding affinities by several orders of magnitude (Bella et al. 2008), we infer that the positive selection sites in the MLA LRR are the main determinants of recognition specificity. Allelic $R$ specificities that function by direct recognition of cognate effectors are expected to be under diversifying selection (Wang et al. 2007). Thus, our study provides some indirect evidence for direct binding of polymorphic but, presumably, structurally related effectors by MLA proteins. These predictions await future biochemical studies.

\section{MATERIALS AND METHODS}

\section{Plant material and barley powdery mildew isolates.}

The plant material used for this study was derived from inbred seed obtained from the stock centers at the IPK (Leipniz Institute of Plant Genetics and Crop Plant Research), Gatersleben (Germany), NGB (The Nordic Gene Bank) (Sweden), United States Department of Agriculture National Small Grains Research Facility (United States), and the Institut National de la Recherche Agronomique-Clermont (France). New candidate MLA cDNAs were isolated from barley cultivars described in Table 1. No Mla amplicons could be obtained from the following lines: RS 170-47 $\times$ Kiebitz B (Mla17), Diamant $\times 1 \mathrm{~B}-20($ Mla26), and 110-4 $\times$ Sonja (Mla29). The B. graminis f. sp. hordei strains A6 and K1 were maintained on barley cvs. Pallas P01 or on Pallas P03, respectively (Shen et al. 2003). These are known to harbor different subsets of $\mathrm{AVR}_{\mathrm{A}}$ effectors (K1: AvrMla1, AvrMla3, AvrMla7, AvrMla13, and AvrMla22; A6: AvrMla3, AvrMla6, AvrMla7, AvrMla9, AvrMla10, AvrMla12, and AvrMla13) (Bieri et al. 2004). The strains DH14 and CC52 were maintained on barley cv. Golden Promise. These were used for a subset of the transient gene-expression experiments (Fig. 4) and to determine infection phenotypes for a subset of accessions and cultivars listed in Table 1. For all experiments, plant material or detached leaves with or without fungal spores were kept at $20^{\circ} \mathrm{C}, 70 \%$ relative humidity, and a cycle of $16 \mathrm{~h}$ of light and $8 \mathrm{~h}$ of darkness.

\section{Isolation and cloning of MLA cDNAs.}

RNA was extracted from 7-day-old barley seedlings with TRIzol Reagent (Invitrogen) and cDNA was produced using 5 $\mu \mathrm{g}$ of total RNA in a final reaction volume of $10 \mu \mathrm{l}$ by the $\mathrm{Su}-$ perscript III reverse transcriptase (Invitrogen), following the manufacturer's protocols. 3'-RACE, 3'-UTR PCR, and cDNA PCR amplifications were carried out using the Expand High Fidelity ${ }^{\text {PLUS }}$ PCR System (Roche) following the manufacturer's manual. To amplify the 3-kb-long cDNA fragment, 5\% dimethly sulfoxide was included in the $50-\mu \mathrm{PCR}$ reaction mix and $2 \mu \mathrm{l}$ of $5 \times$ diluted cDNA was used as a template. All PCR reactions were performed in a PTC-200 thermocycler (Bio-Rad). The amplification conditions to obtain $3^{\prime}$-RACE products using the primers sbi178 (5'-CCACGCAGATATTGTTTG- $\left.3^{\prime}\right)$ and sbi480 $\left(5^{\prime}\right.$-GGATCC $\left.(\mathrm{T})_{31^{-}} 3^{\prime}\right)$ were $2 \mathrm{~min}$ at $94^{\circ} \mathrm{C}$; followed by $35 \mathrm{cy}$ cles of $20 \mathrm{~s}$ at $94^{\circ} \mathrm{C}, 30 \mathrm{~s}$ at $50^{\circ} \mathrm{C}$, and $90 \mathrm{~s}$ at $72^{\circ} \mathrm{C}$; and then a final extension for $7 \mathrm{~min}$ at $72^{\circ} \mathrm{C}$. $3^{\prime}$-UTR PCR was carried out as an alternative strategy to $3^{\prime}$-RACE using primers sse011 (5'-GATGGATCCTGCCATTTAAAAGAAGCTCATCAC-3') and sse012 (5'-GCGCAAGCTTCAACGGCTGCTAGTCATC C-3') with the same PCR conditions as for $3^{\prime}$-RACE. The approximately 600-bp-long 3'-RACE or 3'-UTR PCR amplification products were purified by the GenElute Gel Extraction Kit (Sigma-Aldrich) and cloned using the pGEM-T Easy vector systems (Promega Corp.) following the manufacturer's protocols. To amplify the 23 different candidate MLA variants using cDNA as a template, primers listed in Supplementary Table 1 were used. The PCR conditions were $2 \mathrm{~min}$ at $94^{\circ} \mathrm{C}$; followed by 10 cycles of $20 \mathrm{~s}$ at $94^{\circ} \mathrm{C}, 30 \mathrm{~s}$ at $50^{\circ} \mathrm{C}$, and $4 \mathrm{~min}$ at $68^{\circ} \mathrm{C}$; followed by 20 cycles of $20 \mathrm{~s}$ at $94^{\circ} \mathrm{C}$ and $30 \mathrm{~s}$ at $55^{\circ} \mathrm{C}$; the elongation time was 4 min plus an additional $10 \mathrm{~s}$ for every additional cycle at $68^{\circ} \mathrm{C}$; and then a final extension for $7 \mathrm{~min}$ at $68^{\circ} \mathrm{C}$. The $3-\mathrm{kb}$-long PCR amplification products were purified using the GenElute Gel Extraction Kit and were cloned in a modified pENTR4 (Invitrogen) containing an ubiquitin promoter. Amplification products and the vector were digested with the restriction enzymes AscI and NotI (New England Biolabs) and ligated. All isolated candidate MLA cDNAs were verified by a second independent amplification step from newly generated cDNA. Thus, a $25-\mu \mathrm{l}$ PCR mix was obtained using the Expand High Fidelity ${ }^{\text {PLUS }}$ PCR System under the same conditions mentioned above and, after $2 \mathrm{~min}$ at $94^{\circ} \mathrm{C}$; six cycles of $20 \mathrm{~s}$ at $94^{\circ} \mathrm{C}, 30 \mathrm{~s}$ at $50^{\circ} \mathrm{C}$, and $4 \mathrm{~min}$ at $68^{\circ} \mathrm{C}$; followed by $7 \mathrm{~min}$ at $68^{\circ} \mathrm{C}$, the generated product was used as a template for the PfuUltra high-fidelity DNA polymerase (Stratagene). These specific PCR reactions contained $1 \mu \mathrm{l}$ of the generated template, $5 \mu \mathrm{l}$ of buffer, $3 \mathrm{mM} \mathrm{MgCl}_{2}, 200 \mu \mathrm{M}$ each dNTP, $0.4 \mu \mathrm{M}$ each primer, $10 \%$ glycerol, and 2.5 units of polymerase in a final volume of $50 \mu \mathrm{l}$. The amplification conditions were $2 \mathrm{~min}$ at $94^{\circ} \mathrm{C}$; followed by 32 cycles of $20 \mathrm{~s}$ at $94^{\circ} \mathrm{C}, 30 \mathrm{~s}$ at $50^{\circ} \mathrm{C}$, and $10 \mathrm{~min}$ at $68^{\circ} \mathrm{C}$; and then a final extension for $7 \mathrm{~min}$ at $68^{\circ} \mathrm{C}$. All PCR-generated clones were sequenced using Big Dye Terminator V3.1 following the manufacturer's protocol on an ABI3730 automated sequencer (Applied Biosystems). To exclude possible errors introduced by PCR, six clones from two independent amplification events were sequenced to verify each isolated MLA cDNA. Because a PCR primer derived from the coding region of HcMlal was used to amplify Mla18-1, the 5' end directly after the start codon was confirmed as follows: $5^{\prime}$-RACE was carried out with the SMART RACE cDNA Amplification Kit (Clontech) following the manufacturer's instructions. The PrimeScript reverse transcriptase (Takara) was used to generate cDNA from isolated RNA of cv. RS20-1 $\times$ Kiebitz. The gene-specific primer sse078 (5'-CCTGTCGACCTTGTCCCGCGGCAC-3') was designed for $5^{\prime}$-RACE. The touchdown conditions for $5^{\prime}$-RACE were 5 cycles of $30 \mathrm{~s}$ at $94^{\circ} \mathrm{C}$ and $3 \mathrm{~min}$ at $72^{\circ} \mathrm{C} ; 5$ cycles of $30 \mathrm{~s}$ at $94^{\circ} \mathrm{C}, 30 \mathrm{~s}$ at $70^{\circ} \mathrm{C}$, and $3 \mathrm{~min}$ at $72^{\circ} \mathrm{C}$ after $2 \mathrm{~min}$ at $94^{\circ} \mathrm{C}$; followed by 25 cycles of $30 \mathrm{~s}$ at $94^{\circ} \mathrm{C}, 30 \mathrm{~s}$ at $68^{\circ} \mathrm{C}$, and $3 \mathrm{~min}$ at $72^{\circ} \mathrm{C}$; followed by $7 \mathrm{~min}$ at $72^{\circ} \mathrm{C}$.

\section{Single-cell transient gene-expression assay.}

The single-cell transient gene-expression assay was carried out as described previously, with some modifications (Schweizer et al. 1999; Zhou et al. 2001). After seed vernaliza- 
tion at $4{ }^{\circ} \mathrm{C}$ for $24 \mathrm{~h}$, barley cv. Ingrid mlo5 was grown for 6 days in a growth chamber. The reporter plasmid pV26-UMUG (Bieri et al. 2004) encoded the $\beta$-glucuronidase (GUS) gene and the Mlo gene controlled by the ubiquitin promoter. The gold particles $(1.0 \mu \mathrm{m}$ in diameter; Bio-Rad) were coated with a mixture of reporter plasmid and pENTR-containing Mla, controlled by a ubiquitin promoter, in a molar ratio of $1: 1$ to a total of $2 \mu \mathrm{g}$. Single leaves were transformed with a particle inflow gun (PDS-1000/He; Bio-Rad) and, after 4 h, inoculated with conidiospores of an appropriate powdery mildew isolate at high inoculation density. Single-cell interaction sites between GUS-expressing cells and powdery mildew sporelings were inspected by light microscopy (Shen et al. 2003). An epidermal GUS-expressing cell attacked by a fungal sporeling without a haustorium was counted as an incompatible interaction, whereas the presence of a mature haustorium was counted as a compatible interaction.

\section{Southern blot analysis.}

Isolation of genomic DNA from 33 barley cultivars and Southern hybridization were performed (Travella et al. 2006). The genomic DNA was digested with EcoRI (New England Biolabs) before hybridization with the probe. The primers sbi398 5'-TGATGCGGCCGCAAATCCTTCGGCCACCCAC$3^{\prime}$ and sbi327 5'-CTTGGATCCTGATGCTAGGCAGTCGGCT AATCAC-3' were used to amplify a 501-bp-long probe (Fig. 3 ) from the region encoding the NB domain of Mlal derived from the template cosmid p6-49-2 (Zhou et al. 2001) with Taq DNA Polymerase (Sigma-Aldrich) following the manufacturer's instructions.

\section{Data analysis.}

PAML4 (Yang 2007) was used for the estimation of the nonsynonymous/synonymous ratio for the sequences. The likelihood of more complex models was compared with null models M0 (which assumes neutral codon evolution) and M1a (nearly neutral codon evolution with two codon classes allowed to take on values from $0 \leq d_{\mathrm{N}} / d_{\mathrm{S} 0} \leq 1$ or $d_{\mathrm{N}} / d_{\mathrm{S} 0}=1$ ) with those of a more complex model, M2a, which incorporates an additional positively selected sites class $\left(d_{N} / d_{\mathrm{S}}>1\right)$, and M3 (which assumes three site classes). We also examined the results of analyses using model M7 and M8, which both assume a $\beta$-distribution for $0 \leq d_{\mathrm{N}} / d_{\mathrm{S}} \leq 1$, with the latter model allowing for an extra class of sites with $d_{N} / d_{\mathrm{S}}>1$. We tested for positive selection by comparing the log-likelihood differences in three contrasts: M0 versus M3, M1a versus M2a, and M7 and M8. The codeml package of PAML4 was used to calculate posterior probabilities of codon sites that are under positive selection. We calculated p.p. that each codon site belongs to one of the selection classes. Codons with a significant p.p. $(>0.95)$ of being in a positively selected class $\left(d_{N} / d_{\mathrm{S}}>1\right)$ are considered likely to have experienced positive selection detected all in M2a (Bayes empirical Bayes method), M3, and M8 (Bayes empirical Bayes method). Amino acid positions 822 and 823 (for MLA1) were removed from all these positive-selection analyses because of alignment ambiguity. Phylogenetic trees generated for PAML4 analysis were calculated using MEGA4 (Tamura et al. 2007) for NJ phylogenetic trees and Phylip 3.67 (Felsenstein 1989) for Kimura 2-parameter models and for MP trees. Gene conversion was detected with GENECONV version 1.81a (Sawyer et al. 1999). Global P values were assigned based on 10,000 permutations and corrected for multiple comparisons. Polymorphic residues shown in Figure 1 were analyzed and illustrated by original Perl scripts. DNA sequence data was analyzed with Clone Manager Profession Suite version 8 and alignments were modified in GeneDoc version 2.7 (Nicholas et al. 1997). CCs were analyzed with COILS version 2.2 (Lupas et al. 1991). The EMBOSS suite (Rice et al. 2000) was used to search for LRR motifs. They were confirmed by secondary structure prediction using the PSIPRED and SCRATCH server (Bryson et al. 2005; Cheng et al. 2005).

\section{ACKNOWLEDGMENTS}

We thank S. Sasso, S. Aoki, and H. Araki for helpful discussions; T. Wicker for providing his software to depict data shown in Figure 1 and for sequence analysis; F. Ceron for cloning and sequencing HcMlal; C. Ridout for the gift of powdery mildew isolates DH14 and CC52; and K. Macaulay for proofreading parts of the text. Financial support for this work was provided by Swiss National Science Foundation grant no. 31003A-109361 to $\mathrm{S}$. Bieri and B. Keller and by the research fellowship for Young Scientists of the Japan Society for the Promotion of Science to T. Tsuchimatsu and the University Research Priority Program Systems Biology/Functional Genomics of University of Zurich to K. K. Shimizu. The Danish Ministry of Food, Agriculture and Fisheries provided support to A. Jahoor. S. Pajonk was supported by a Ph.D. fellowship (International Max Planck Graduate Research School) from the Max Planck Society and P. Schulze-Lefert is supported by the Max Planck Society, the Deutsche Forschungsgemeinschaft (SFB670), and a European Union-BIOEXPLOIT grant.

\section{LITERATURE CITED}

Allen, R. L., Bittner-Eddy, P. D., Grenvitte-Briggs, L. J., Meitz, J. C. Rehmany, A. P., Rose, L. E., and Beynon, J. L. 2004. Host-parasite coevolutionary conflict between Arabidopsis and downy mildew. Science 306:1957-1960.

Allen, R. L., Meitz, J. C., Baumber, R. E., Hall, S. A., Lee, S. C., Rose, L. E., and Beynon, J. L. 2008. Natural variation reveals key amino acids in a downy mildew effector that alters recognition specificity by an Arabidopsis resistance gene. Mol. Plant Pathol. 9:511-523.

Bella, J., Hindle, K. L., McEwan, P. A., and Lovell, S. C. 2008. The leucine-rich repeat structure. Cell. Mol. Life Sci. 65:2307-2333.

Bieri, S., Mauch, S., Shen, Q. H., Peart, J., Devoto, A., Casais, C., Ceron, F., Schulze, S., Steinbiss, H. H., Shirasu, K., and Schulze-Lefert, P. 2004. RAR1 positively controls steady state levels of barley MLA resistance proteins and enables sufficient MLA6 accumulation for effective resistance. Plant Cell 16:3480-3495.

Botella, M. A., Parker, J. E., Frost, L. N., Bittner-Eddy, P. D., Beynon, J. L., Daniels, M. J., Holub, E. B., and Jones, J. D. G. 1998. Three genes of the Arabidopsis RPP1 complex resistance locus recognize distinct Peronospora parasitica avirulence determinants. Plant Cell 10:1847-1860.

Boyd, L. A., Smith, P. H., Foster, E. M., and Brown, J. K. M. 1995. The effects of allelic variation at the Mla resistance locus in barley on the early development of Erysiphe graminis f. sp. hordei and host responses. Plant J. 7:959-968.

Bryson, K., McGuffin, L. J., Marsden, R. L., Ward, J. J., Sodhi, J. S., and Jones, D. T. 2005. Protein structure prediction servers at University College London. Nucleic Acids Res. 33:W36-W38.

Caicedo, A. L., and Schaal, B. A. 2004. Heterogeneous evolutionary processes affect $\mathrm{R}$ gene diversity in natural populations of Solanum pimpinellifolium. Proc. Natl. Acad. Sci. U.S.A. 101:17444-17449.

Cheng, J., Randall, A. Z., Sweredoski, M. J., and Baldi, P. 2005. SCRATCH: A protein structure and structural feature prediction server. Nucleic Acids Res. 33:W72-W76.

DeYoung, B. J., and Innes, R. W. 2006. Plant NBS-LRR proteins in pathogen sensing and host defense. Nat. Immunol. 7:1243-1249.

Dheeranupattana, S. 1995. Untersuchungen zur Vererbung der Mehltauresistenz bei Gerste. Dissertation, München Technische Universität, Germany.

Dodds, P. N., Lawrence, G. J., Catanzariti, A. M., Ayliffe, M. A., and Ellis, J. G. 2004. The Melampsora lini AvrL567 avirulence genes are expressed in haustoria and their products are recognized inside plant cells. Plant Cell 16:755-768.

Dodds, P. N., Lawrence, G. J., Catanzariti, A. M., Teh, T., Wang, C. I. A., Ayliffe, M. A., Kobe, B., and Ellis, J. G. 2006. Direct protein interaction underlies gene-for-gene specificity and coevolution of the flax resistance genes and flax rust avirulence genes. Proc. Natl. Acad. Sci. U.S.A. 103:8888-8893.

Dunning, F. M., Sun, W., Jansen, K. L., Helft, L., and Bent, A. F. 2007. Identification and mutational analysis of Arabidopsis FLS2 leucine-rich repeat domain residues that contribute to flagellin perception. Plant Cell 19:3297-3313.

Ellis, J., Dodds, P., and Pryor, T. 2000. Structure, function and evolution of plant disease resistance genes. Curr. Opin. Plant Biol. 3:278-284. 
Ellis, J. G., Lawrence, G. J., Luck, J. E., and Dodds, P. N. 1999. Identification of regions in alleles of the flax rust resistance gene $L$ that determine differences in gene-for-gene specificity. Plant Cell 11:495-506.

Ellis, J. G., Dodds, P. N., and Lawrence, G. J. 2007. Flax rust resistance gene specificity is based on direct resistance-avirulence protein interactions. Annu. Rev. Phytopathol. 45:289-306.

Felsenstein, J. 1989. PHYLIP-phylogeny inference package (version 3.2). Cladistics 5:164-166.

Giese, H., Jorgensen, J. H., Jensen, H. P., and Jensen, J. 1981. Linkage relationships of ten powdery mildew resistance genes on barley chromosome 5. Hereditas 95:43-50.

Halterman, D., Zhou, F. S., Wei, F. S., Wise, R. P., and Schulze-Lefert, P. 2001. The MLA6 coiled-coil, NBS-LRR protein confers AvrMla6dependent resistance specificity to Blumeria graminis f. sp hordei in barley and wheat. Plant J. 25:335-348.

Halterman, D. A., and Wise, R. P. 2004. A single-amino acid substitution in the sixth leucine-rich repeat of barley MLA6 and MLA13 alleviates dependence on RAR1 for disease resistance signaling. Plant J. 38:215226.

Halterman, D. A., Wei, F. S., and Wise, R. P. 2003. Powdery mildewinduced Mla mRNAs are alternatively spliced and contain multiple upstream open reading frames. Plant Physiol. 131:558-567.

Jahoor, A., and Fischbeck, G. 1987. Genetical studies of resistance of powdery mildew in barley lines derived from Hordeum spontaneum collected from Israel. Plant Breed. 99:265-273.

Jahoor, A., and Fischbeck, G. 1993. Identification of new genes from mildew resistance of barley at the Mla locus in lines derived from Hor deum spontaneum. Plant Breed. 110:116-122.

Jones, J. D. G., and Dang1, J. L. 2006. The plant immune system. Nature 444:323-329.

Jorgensen, J. H. 1993. Coordinator's report: Disease and pest resistant genes. Pages 110-133 in: Barley Genetics Newsletter, Vol. 22. Plant Genetics Section, Environmental Science and Technology Department, Ris $\emptyset$ National Laboratory, Roskilde, Denmark.

Jorgensen, J. H. 1994. Genetics of powdery mildew resistance in barley. Crit. Rev. Plant Sci. 13:97-119.

Jorgensen, J. H., and Moseman, H. P. 1972. Recombination at the Ml-a locus in barley conditioning resistance to Erysiphe graminis f. sp. hordei. Can. J. Genet. Cytol. 14:43-48.

Kajava, A. V., Vassart, G., and Wodak, S. J. 1995. Modeling of the threedimensional structure of proteins with the typical leucine-rich repeats Structure 3:867-877.

Kim, H. M., Park, B. S., Kim, J. I., Kim, S. E., Lee, J., Oh, S. C., Enkhbayar, P., Matsushima, N., Lee, H., Yoo, O. J., and Lee, J. O. 2007. Crystal structure of the TLR4-MD-2 complex with bound endotoxin antagonist eritoran. Cell 130:906-917.

Kintzios, S., Jahoor, A., and Fischbeck, G. 1995. Powdery-mildew-resistance genes Mla29 and Mla32 in H. spontaneum derived winter-barley lines. Plant Breed. 114:265-266.

Kobe, B., and Kajava, A. V. 2001. The leucine-rich repeat as a protein recognition motif. Curr. Opin. Struct. Biol. 11:725-732.

Leckie, F., Mattei, B., Capodicasa, C., Hemmings, A., Nuss, L., Aracri, B., De Lorenzo, G., and Cervone, F. 1999. The specificity of polygalacturonase-inhibiting protein (PGIP): A single amino acid substitution in the solvent-exposed beta-strand/beta-turn region of the leucinerich repeats (LRRs) confers a new recognition capability. EMBO (Eur. Mol. Biol. Organ.) J. 18:2352-2363.

Luck, J. E., Lawrence, G. J., Dodds, P. N., Shepherd, K. W., and Ellis, J. G. 2000. Regions outside of the leucine-rich repeats of flax rust resistance proteins play a role in specificity determination. Plant Cell 12:1367-1377.

Lupas, A., Vandyke, M., and Stock, J. 1991. Predicting coiled coils from proteins sequences. Science 252:1162-1164.

McDowell, J. M., Dhandaydham, M., Long, T. A., Aarts, M. G. M., Goff, S., Holub, E. B., and Dangl, J. L. 1998. Intragenic recombination and diversifying selection contribute to the evolution of downy mildew resistance at the RPPS locus of Arabidopsis. Plant Cell 10:1861-1874.

Meyers, B. C., Chin, D. B., Shen, K. A., Sivaramakrishnan, S., Lavelle, D. O., Zhang, Z., and Michelmore, R. W. 1998. The major resistance gene cluster in lettuce is highly duplicated and spans several megabases. Plant Cell 10:1817-1832.

Mondragon-Palomino, M., Meyers, B. C., Michelmore, R. W., and Gaut, B. S. 2002. Patterns of positive selection in the complete NBS-LRR gene family of Arabidopsis thaliana. Genome Res. 12:1305-1315.

Nicholas, K. B., Nicholas, H. B. J., and Deerfield, D. W. I. 1997. GeneDoc:
Analysis and visualization of genetic variation EMBNEW.NEWS 4:14

Noel, L., Moores, T. L., van der Biezen, E. A., Parniske, M., Daniels, M. J., Parker, J. E., and Jones, J. D. G. 1999. Pronounced intraspecific haplotype divergence at the RPP5 complex disease resistance locus of Arabidopsis. Plant Cell 11:2099-2111.

Parniske, M., HammondKosack, K. E., Golstein, C., Thomas, C. M., Jones, D. A., Harrison, K., Wulff, B. B. H., and Jones, J. D. G. 1997. Novel disease resistance specificities result from sequence exchange between tandemly repeated genes at the $C f-4 / 9$ locus of tomato. Cell 91:821-832.

Rice, P., Longden, I., and Bleasby, A. 2000. EMBOSS: The European molecular biology open software suite. Trends Genet. 16:276-277.

Ridout, C. J., Skamnioti, P., Porritt, O., Sacristan, S., Jones, J. D. G., and Brown, J. K. M. 2006. Multiple avirulence paralogues in cereal powdery mildew fungi may contribute to parasite fitness and defeat of plant resistance. Plant Cell 18:2402-2414.

Rose, L. E., Bittner-Eddy, P. D., Langley, C. H., Holub, E. B., Michelmore, R. W., and Beynon, J. L. 2004. The maintenance of extreme amino acid diversity at the disease resistance gene, RPP13, in Arabidopsis thaliana. Genetics 166:1517-1527.

Saisho, D., and Purugganan, M. D. 2007. Molecular phylogeography of domesticated barley traces expansion of agriculture in the Old World. Genetics 177:1765-1776.

Sawyer, S. A. 1999. GENECONV: A Computer Package for the Statistical Detection of Gene Conversion. Barley Genetics Newsletter. Published online.

Schweizer, P., Pokorny, J., Abderhalden, O., and Dudler, R. 1999. A transient assay system for the functional assessment of defense-related genes in wheat. Mol. Plant-Microbe Interact. 12:647-654.

Schwessinger, B., and Zipfel, C. 2008. News from the frontline: Recent insights into PAMP-triggered immunity in plants. Curr. Opin. Plant Biol. 11:389-395.

Shen, Q. H., and Schulze-Lefert, P. 2007. Rumble in the nuclear jungle: Compartmentalization, trafficking, and nuclear action of plant immune receptors. EMBO (Eur. Mol. Biol. Organ.) J. 26:4293-4301.

Shen, Q. H., Zhou, F. S., Bieri, S., Haizel, T., Shirasu, K., and SchulzeLefert, P. 2003. Recognition specificity and RAR1/SGT1 dependence in barley Mla disease resistance genes to the powdery mildew fungus. Plant Cell 15:732-744.

Shen, Q. H., Saijo, Y., Mauch, S., Biskup, C., Bieri, S., Keller, B., Seki, H., Ulker, B., Somssich, I. E., and Schulze-Lefert, P. 2007. Nuclear activity of MLA immune receptors links isolate-specific and basal disease-resistance responses. Science 315:1098-1103.

Tamura, K., Dudley, J., Nei, M., and Kumar, S. 2007. MEGA4: Molecular evolutionary genetics analysis (MEGA) software version 4.0. Mol. Biol. Evol. 24:1596-1599.

Tan, X., Calderon-Villalobos, L. I. A., Sharon, M., Zheng, C. X., Robinson, C. V., Estelle, M., and Zheng, N. 2007. Mechanism of auxin perception by the TIR1 ubiquitin ligase. Nature 446:640-645.

Travella, S., Klimm, E., and Keller, B. 2006. RNAi based gene silencing as an efficient tool for functional genomics in hexaploid bread wheat (Triticum aestivum L.). Plant Physiol. 142:6-20.

Van Ooijen, G., Mayr, G., Kasiem, M. M. A., Albrecht, M., Cornelissen, B. J. C., and Takken, F. L. W. 2008. Structure-function analysis of the NB-ARC domain of plant disease resistance proteins. J. Exp. Bot. 59:1383-1397.

Wang, C. I. A., Guncar, G., Forwood, J. K., Teh, T., Catanzariti, A. M., Lawrence, G. J., Loughlin, F. E., Mackay, J. P., Schirra, H. J., Anderson, P. A., Ellis, J. G., Dodds, P. N., and Kobe, B. 2007. Crystal structures of flax rust avirulence proteins AvrL567-A and -D reveal details of the structural basis for flax disease resistance specificity. Plant Cell 19:2898-2912.

Wei, F. S., Wong, R. A., and Wise, R. P. 2002. Genome dynamics and evolution of the Mla (powdery mildew) resistance locus in barley. Plant Cell 14:1903-1917.

Wise, R. P., and Ellingboe, A. H. 1985. Fine structure and instability of the Mla locus in barley. Genetics 111:113-130.

Yahiaoui, N., Brunner, S., and Keller, B. 2006. Rapid generation of new powdery mildew resistance genes after wheat domestication. Plant $\mathrm{J}$. 47:85-98.

Yang, Z. 2007. PAML 4: A program package for phylogenetic analysis by maximum likelihood. Mol. Biol. Evol. 24:1586-1591.

Zhou, F. S., Kurth, J. C., Wei, F. S., Elliott, C., Vale, G., Yahiaoui, N., Keller, B., Somerville, S., Wise, R., and Schulze-Lefert, P. 2001. Cellautonomous expression of barley Mlal confers race-specific resistance to the powdery mildew fungus via a Rar1-independent signaling pathway. Plant Cell 13:337-350. 